c. 2

\section{Corps}

sers

Waterways Experiment

Station

\title{
Solid Residuals Management at Centralized Vehicle Wash Facilities
}

by Trudy J. Olin, Kurt T. Preston

Approved For Public Release; Distribution Is Unlimited






\title{
Solid Residuals Management at Centralized Vehicle Wash Facilities
}

\author{
by Trudy J. Olin, Kurt T. Preston \\ U.S. Army Corps of Engineers \\ Waterways Experiment Station \\ 3909 Halls Ferry Road \\ Vicksburg, MS 39180-6199
}

Final report

Approved for public release; distribution is unlimited

Prepared for U.S. Army Construction Engineering

Research Laboratories

Champaign, IL 61826-9005 


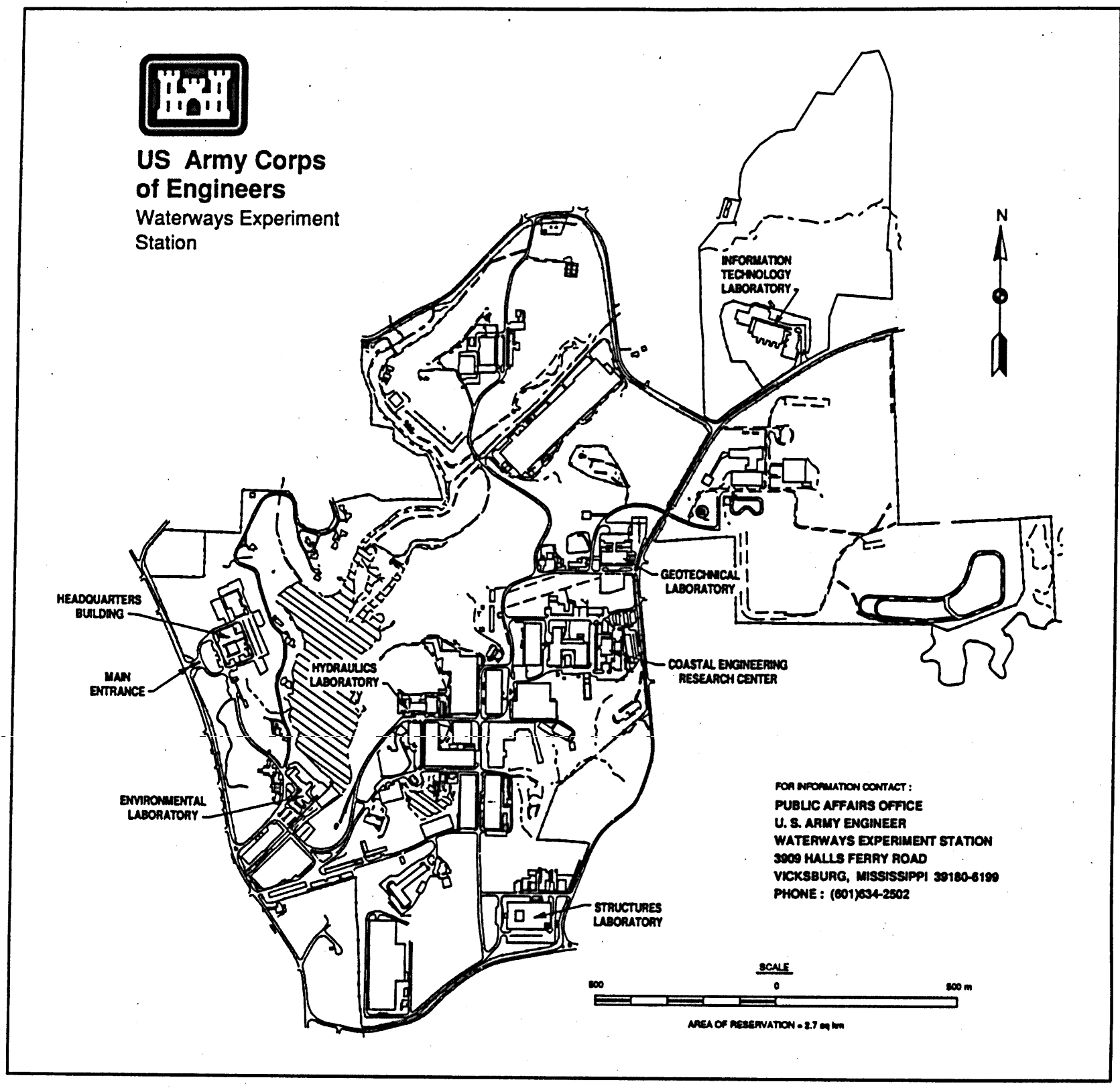

Waterways Experiment Station Cataloging-in-Publication Data

Olin, Trudy J.

Solid residuals management at centralized vehicle wash facilities / by Trudy J. Olin, Kurt T. Preston ; prepared for U.S. Army Construction Engineering Research Laboratories.

66 p. : ill. ; $28 \mathrm{~cm}$. - (Miscellaneous paper ; EL-95-4)

Includes bibliographic references.

1. Soil pollution. 2. Sedimentation and deposition. 3. Vehicles, Military-

Cleaning. I. Preston, Kurt T. II. United States. Army. Corps of Engineers. III.

U.S. Army Engineer Waterways Experiment Station. IV. Environmental Laboratory

(U.S. Army Engineer Waterways Experiment Station) V. Construction Engineering

Research Laboratories (U.S.) VI. Title. VII. Series: Miscellaneous paper (U.S.

Army Engineer Waterways Experiment Station) ; EL-95-4.

TA7 W34m no.EL-95-4 


\section{Contents}

Preface $\ldots \ldots \ldots \ldots \ldots \ldots \ldots \ldots \ldots \ldots \ldots$ vi

Conversion Factors, Non-SI to SI Units

of Measurement ........................ vii

Summary $\ldots \ldots \ldots \ldots \ldots \ldots \ldots \ldots \ldots \ldots$ viii

1-Introduction $\ldots \ldots \ldots \ldots \ldots \ldots \ldots \ldots \ldots \ldots \ldots \ldots \ldots \ldots \ldots$



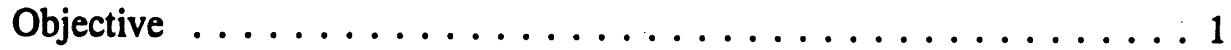

History of CVWF ....................

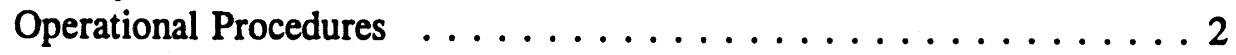

Residuals Management . . . . . . . . . . . . . . . 2

Operational Problems ................... 5

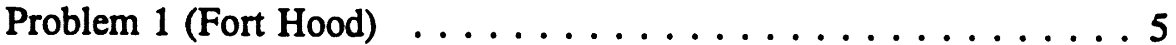

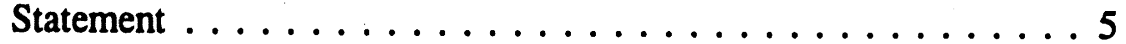

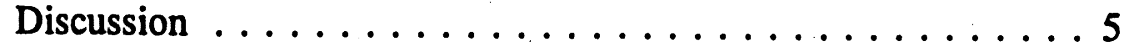

Problem 2 (Fort Hood) $\ldots \ldots \ldots \ldots \ldots \ldots \ldots \ldots$

Statement ..................

Discussion .................. 5

Problem 3 (Fort Hood) . . . . . . . . . . . . . 6

Statement ..................6

Discussion ...................6

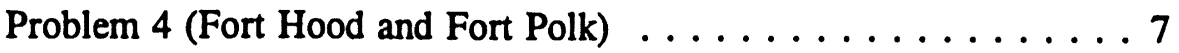

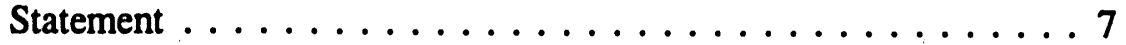

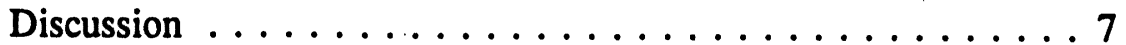

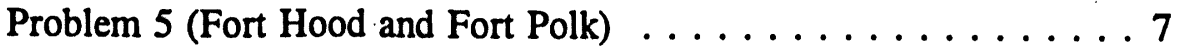



Discussion ................... 9

2-Technologies ...................... 10

Regulatory Requirements . . . . . . . . . . . . . . 10

Testing ......................... 10

Sampling ...................... 11

Wildco hand corer $\ldots \ldots \ldots \ldots \ldots \ldots \ldots \ldots \ldots \ldots \ldots \ldots$

Lexan tube samplers $\ldots \ldots \ldots \ldots \ldots \ldots \ldots \ldots \ldots$ 
Physical/Chemical Treatments ................. 13

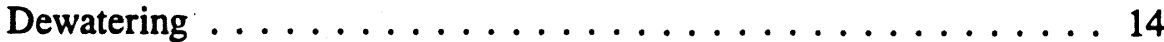

Primary settling $\ldots \ldots \ldots \ldots \ldots \ldots \ldots \ldots \ldots$

Surface drainage $\ldots \ldots \ldots \ldots \ldots \ldots$

Subsurface drainage $\ldots \ldots \ldots \ldots \ldots \ldots$

Solar evaporation . . . . . . . . . . . . . . 19

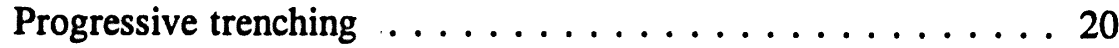

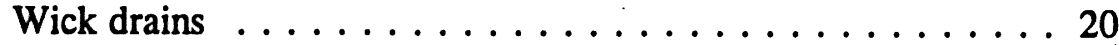

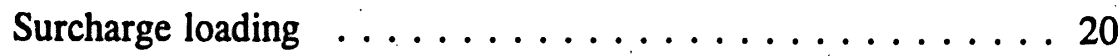

Vertical sand drains ................. 21

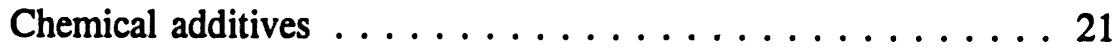

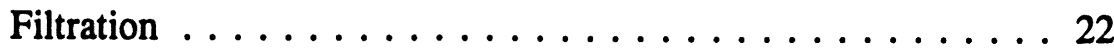

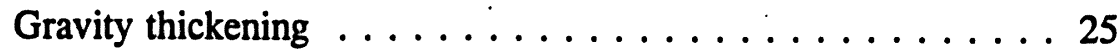

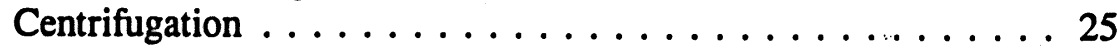



Vegetative desiccation .................. 29

Thin-lift placement . . . . . . . . . . . . . . . . 29

Selection of dewatering technologies for CVWF solids management ..................... 29

Particle separation (classification) $\ldots \ldots \ldots \ldots 33$

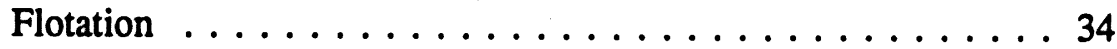

Grizzlies . . . . . . . . . . . . . . . . 35

Hydraulic classifiers .................. 35

Hydrocyclones . . . . . . . . . . . . . 35

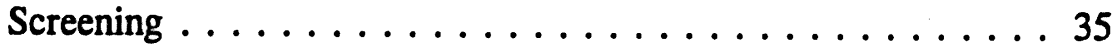



Spiral classifiers .................... 36

Evaluation of classification technologies (solid/solid

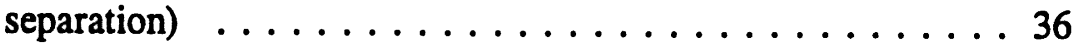

UXE removal $\ldots \ldots \ldots \ldots \ldots \ldots \ldots \ldots$

Treatment of contaminants $\ldots \ldots \ldots \ldots \ldots \ldots$

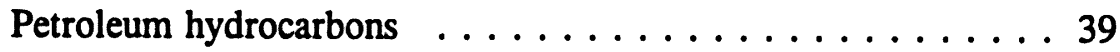

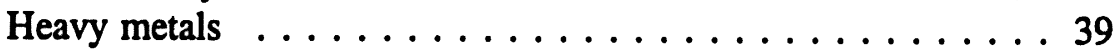

Oil and grease ...................... 40

Biological treatment of CVWF residuals . . . . . . . . . 40

Disposal Without Treatment . . . . . . . . . . . . . 42

3-Recommendations . . . . . . . . . . . . . . . . 43

Solid Residuals Management $\ldots \ldots \ldots \ldots . \ldots \ldots 4$

Dewatering ......................... 43

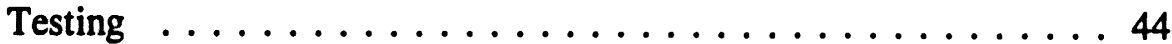

Physical/chemical treatment $\ldots \ldots \ldots \ldots \ldots \ldots 4$

Biological ..................... 44

Solidification/stabilization ............... . . 44

Other comments/recommendations .............. . . 44

Operational Procedures ................... . . 45

Design Modifications . . . . . . . . . . . . . . . . . 45

Testing and Evaluation . . . . . . . . . . . . . 46 
References ....................... 47

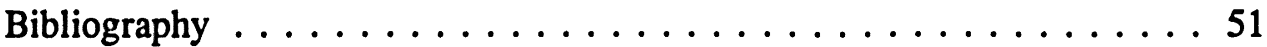

SF 298

\section{List of Figures}

Figure 1. Tracked vehicle entering bath prewash, Fort Hood, Texas . . . 3

Figure 2. Primary sedimentation basin, Fort Hood, Texas . . . . . . . . . 4

Figure 3. Sediment overload and short circuiting, primary sedimentation basin, Fort Hood, Texas . . . . . . . . . . . 6

Figure 4. Fine solid residuals, primary sedimentation basin, Fort Hood, Texas .................... 7

Figure 5. Short circuiting, secondary sedimentation basin, Fort Hood, Texas .................... 8

Figure 6. Secondary sedimentation basins, Fort Hood, Texas . . . . . . 8

Figure 7. Particle size and process solids concentrations . . . . . . . 18

Figure 8. Dependence of cut size $\mathrm{X}_{50}$ on feed concentration and flow rate for nozzle-discharge disc centrifuge . . . . . . . 26

Figure 9. Effect of feed concentration and flow rate on cut size $\mathrm{X}_{50}$ for scroll-type centrifuge $\ldots \ldots \ldots \ldots \ldots \ldots$

Figure 10. Scroll-type centrifuge dewatering performance declines at critical feed rate . . . . . . . . . . . . . . 27

Figure 11. Performance of various centrifugal sedimentation equipment . 28

Figure 12. Particle size as a guide in selection of solid-liquid separation equipment $\ldots \ldots \ldots \ldots \ldots \ldots$

\section{List of Tables}

Table 1. Liquid/Solid Separation Analysis ............. 16

Table 2. Floc Characteristics for Specific Applications . . . . . . . . . 21

Table 3. Summary of Dewatering Technologies . . . . . . . . . . 30

Table 4. Dewatering Technology Rating . . . . . . . . . . . . . 33

Table 5. Treatment Technologies for CVWF Sediments . . . . . . . . 38

Table 6. Reported Hydrocarbon Degradation Rates . . . . . . . . . 41 


\section{Preface}

The report herein was prepared at the U.S. Army Engineer Waterways Experiment Station (WES) in cooperation with the U.S. Army Construction Engineering Research Laboratories (CERL) at the request of Dr. Tom Hart, Headquarters, U.S. Army Corps of Engineers. Portions of this report will be extracted for inclusion in a report to be published by CERL.

Permission to use copyrighted material from Solid-Liquid Separation and Advances in Solid-Liquid Separation was obtained from ButterworthHeinemann, Ltd., and Battelle Press, respectively.

The report was prepared by Ms. Trudy J. Olin of the Engineering Applications Branch (EAB) and Dr. Kurt T. Preston of the Environmental Restoration Branch (ERB), Environmental Engineering Division (EED), Environmental Laboratory (EL), WES, Vicksburg, MS. Technical review was provided by Mr. Norman R. Francingues and Dr. Michael R. Palermo, EL.

The study was conducted under the general supervision of Mr. Francingues, Chief, ERB, Dr. Raymond L. Montgomery, Chief, EED, and Dr. John W. Keeley, Director, EL.

At the time of publication of this report, Director of WES was Dr. Robert W. Whalin. Commander was COL Bruce K. Howard, EN.

This report should be cited as follows:

Olin, T. J., and Preston, K. T. (1995). "Solid residuals management at centralized vehicle wash facilities," Miscellaneous Paper EL-95-4, U.S. Army Engineer Waterways Experiment Station, Vicksburg, MS.

The contents of this report are not to be used for advertising, publication, or promotional purposes. Citation of trade names does not constitute an official endorsement or approval of the use of such commercial products. 


\section{Conversion Factors, Non-SI to SI Units of Measurement}

Non-SI units of measurement used in this report can be converted to SI units as follows:

\begin{tabular}{|l|l|l|}
\hline Multiply & By & To Obtain \\
\hline \hline cubic yards & 0.7645549 & cubic meters \\
\hline feet & 0.3048 & meters \\
\hline inches & 2.54 & centimeters \\
\hline tons (2,000 pounds, mass) & 907.1847 & kilograms \\
\hline
\end{tabular}




\section{Summary}

Solid residuals from centralized vehicle wash facilities (CVWF) present a management problem in materials handling and disposal. The high percentage of fine particles in the solid residuals and the length of time required to dewater these sediments complicate sedimentation basin maintenance. The presence of contaminants in some of these sediments, including heavy metals, petroleum hydrocarbons, oil and grease, and ordnance, imposes testing, treatment and disposal requirements. Solid-residuals management has not been adequately addressed to date, and operational practices vary significantly among facilities. Differences among facilities exist in degree of contamination present and the management problems presented.

Site visits were made to CVWF locations to determine operational parameters and gather field data. A general description of current operational practices and problems is contained in this document. The focus of the study, however, is limited to evaluation of effective management alternatives for solid residuals and peripheral treatment of those elements of facility operations that impact solids management. A literature survey of dewatering and treatment technologies was conducted to facilitate the development of solidresiduals management guidelines. These efforts addressed the following thrust areas:

a. Regulatory requirements.

b. Dewatering technologies.

c. Treatment and disposal alternatives.

d. Operational recommendations.

e. Design modifications.

f. Technology evaluation.

Regulatory requirements vary from State to State and impose differing testing, sampling, treatment, and disposal requirements for solid residuals. Regulatory requirements pertaining to contaminated sediments were reviewed for 
applicability to CVWF solid residuals, and a brief discussion is contained in this document.

Several suitable dewatering technologies exist that could be utilized with CVWF sediments. The principal decision to be made is whether to dewater within the sedimentation basins, which is the current practice, or to remove the wet sediments by pumping and dewater outside of the basins. A progressive field evaluation of dewatering enhancements is recommended to determine the most effective and economic approach. The first three recommendations are directed at improving in-basin dewatering using easily implemented, low-cost approaches. The last recommendation, removal and out-of-basin dewatering, would be implemented if none of the first three alternatives achieved satisfactory results. These recommendations are as follows:

a. Improve surface drainage for removal of maximum surface water.

b. Clean primary sedimentation basins more frequently so that sediment depth is reduced, thereby reducing the drainage path.

c. Employ a permeable underdrainage layer of sand, gravel, or permeable fabric; this may be coupled with vertical drainage devices.

d. Remove the sludge with sludge pumps, and dewater outside of the basin.

Treatment and disposal requirements must be evaluated on a case-by-case basis. Regulatory requirements will dictate the necessary analyses, and results of these analyses will determine subsequent action. Waste stabilization, contaminant treatment, disposal, and beneficial-use alternatives should be evaluated for regulatory, technical, and economic acceptability in each case.

It is further recommended that operational procedures be standardized to establish routine evaluation of sediments consistent with regulatory requirements and to provide for regular maintenance and cleaning of sedimentation basins. All systems should be maintained in working order. Provision for disposal of waste oil at the wash racks is needed to prevent illicit disposal in the wash water and subsequent contamination of sedimentation-basin sediments. Design modifications to the sedimentation basins should be considered where performance could be significantly improved with simple modifications, such as the addition of distribution headers and adjustable weirs.

Evaluation of selected technologies on bench, pilot or field scale is recommended as necessary on a site-by-site basis. 


\section{Introduction}

\section{Background}

The U.S. Army Engineer Waterways Experiment Station, Environmental Laboratory (WES-EL) was asked to conduct a joint literature survey with the U.S. Army Construction Engineering Research Laboratories (CERL) in a review of scientific literature regarding available technologies for the management and treatment of residuals from centralized vehicle wash facilities (CVWFs).

\section{Objective}

The objective of this effort was to conduct a review of relevant scientific and engineering literature associated with the testing, handling, treatment, and disposal of solid residues similar to CVWF residuals, and the development of recommendations for the management of CVWF residuals.

\section{History of CVWF}

A keystone to army vehicle maintenance and unit discipline rests upon the idea that soldiers, operators of army equipment, have an absolute responsibility to keep the equipment clean and in top operational readiness. Historically, each battalion-size unit has a unit wash facility or "wash rack" where vehicles returning from the field-training environment are cleaned prior to placement at the unit motor pool. In the late 1970s, army planners recognized the need to improve the efficiency of traditional vehicle-wash procedures by the construction of centralized vehicle wash facilities (CVWFs). At these points, large numbers of vehicles could be moved and cleaned by the use of water cannons, high-pressure hoses, and partial vehicle immersion. Additionally, by moving primary vehicle cleaning from the traditional wash rack to the CVWF, the treatment processes could be better controlled and monitored. 


\section{Operational Procedures}

The process for vehicles in the CVWF consists, in general, of vehicle queuing, preparation, prewash, wash, and exit. The CVWF is designed with traffic flow as a major concern. Vehicles enter the facility from one point, move through the various cleaning processes in sequence, and depart.

From the users perspective, operations within the CVWF unfold in the following manner. After field training operations, units approach the cantonment area along various unpaved roads called tank trails. By design, CVWFs are constructed adjacent to a major tank trail entering the cantonment area. Arriving in march column, units enter the facility and begin the wash process prior to entering the main post. Lead vehicles are usually met by a wash facility attendant, who informs unit personnel of the status of the CVWF and current procedures. If all is ready, the lead vehicles are guided into position in the preparation area for the initial cleaning. This cleaning consists of a rinse by a high-pressure hose to remove gross outside dirt from between wheels, axles, road wheels, and track blocks. From the preparation area, the vehicle and ground crew guide the vehicle to the prewash. Design standards (Department of the Army 1992) require one of two types of prewash systems: bath prewash or wash stand prewash. The bath prewash is preferred and consists of a water-filled basin through which the vehicle is driven. Cleaning in the prewash is accomplished by the combined force of wave action and relative water movement from the vehicle in the bath, scouring from water cannons, and flexors mounted on the bottom of the basin (see Figure 1). The flexors work the submerged vehicle suspension system and force material into the bath water. Vehicles departing the bath prewash are guided into the wash stations where detailed washing takes place. Trash cans may also be provided to allow the users to deposit paper products, etc., found during the cleaning process. The vehicle then exits the centralized wash facility and moves into an assembly area or returns by itself to the unit maintenance area.

\section{Residuals Management}

The residue deposited by the vehicles takes a different route. Whether deposited during the preparation, prewash, or wash phase, all contaminated water from the vehicle cleaning process enters the CVWF wastewater treatment process. While the actual configurations are site specific, some generalizations may be made. First, CVWF wastewater treatment systems have been designed to be operationally robust and, to the extent possible, reduce over all facility water utilization requirements by system water recycle. Second, system unit operations may generally be divided into primary and secondary treatment strategies.

Primary treatment systems have two goals. One is the reduction of the concentration of suspended solids in the waste stream. The second is the removal of free oils and greases. To accomplish this dual role, a gravity-fed 


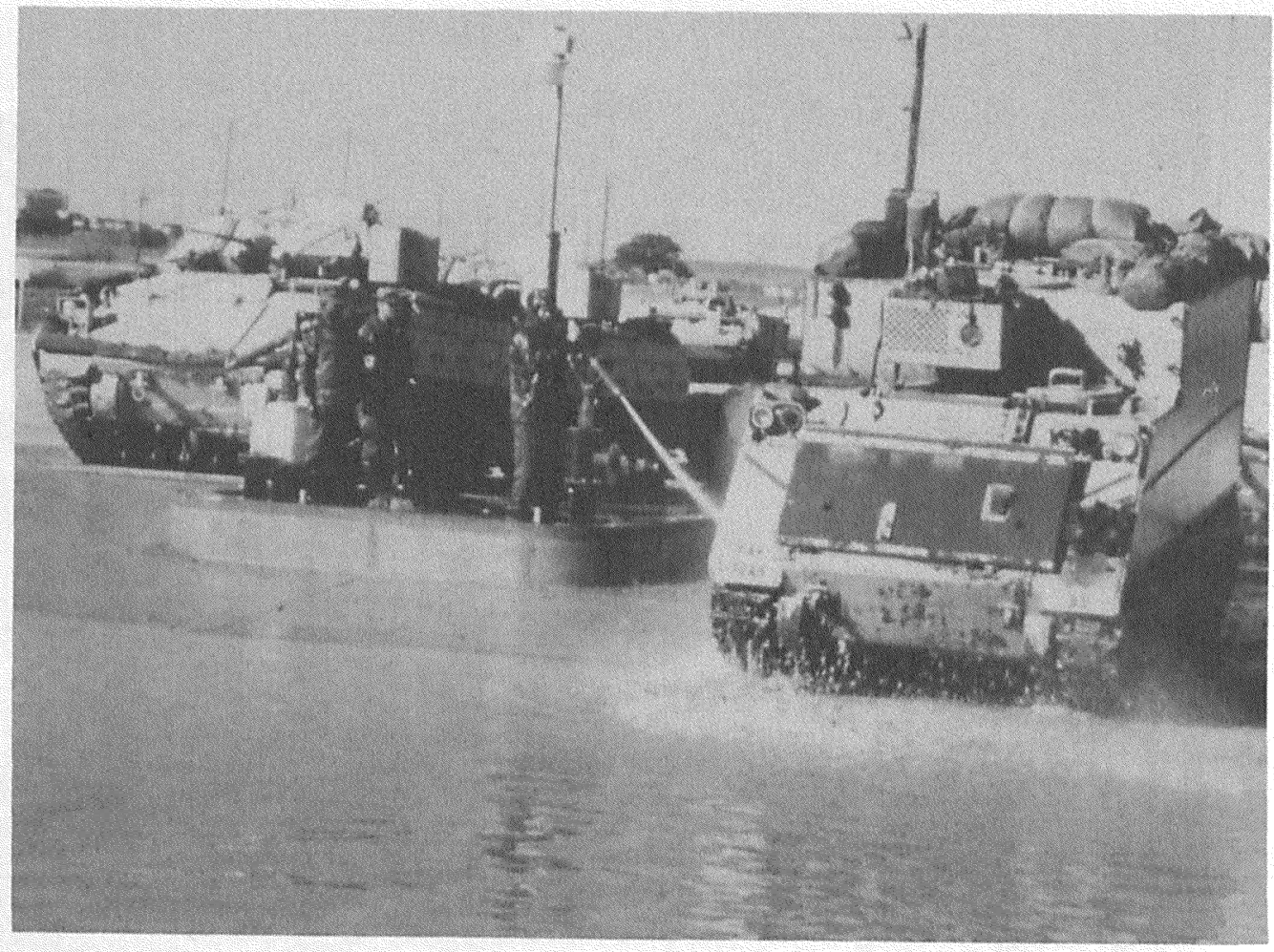

Figure 1. Tracked vehicie entering bath prewash, Fort Hood, Texas

sedimentation basin is normally constructed below the CVWF. This basin may be of either dual- or single-cell construction. If the single-cell construction is selected, CVWF operations must cease during the time that captured sediments are removed from the basin; if a dual cell system is selected, operation may continue with one cell in operation while the second is being cleaned (see Figure 2). The design time between sediment removal operations is 1 year (Department of the Army 1992). Oils and grease are normally collected by mechanical surface skimming, while baffles are maintained near the effluent weir to reduce carryover in the system discharge. Recovered oil is directed into either an above- or below-surface storage tank. All tankage and oil disposal must meet local, State, and Federal environmental regulations.

Cleaning of the primary treatment system normally entails the following steps. First, the CVWF influent is cut off, and the sedimentation basin is allowed a quiescent period during which particle settling occurs. Second, water is drained from the basin "to the maximum extent possible" (Department of the Army 1992). Third, the sediments are physically removed from the settling basin by front-end loaders and dump trucks, which have access to the basin via concrete ramps. The material is then hauled away for disposal under the applicable local, state, and Federal regulations. Wastewater and the materials remaining in the wastewater stream enter the secondary treatment system. 


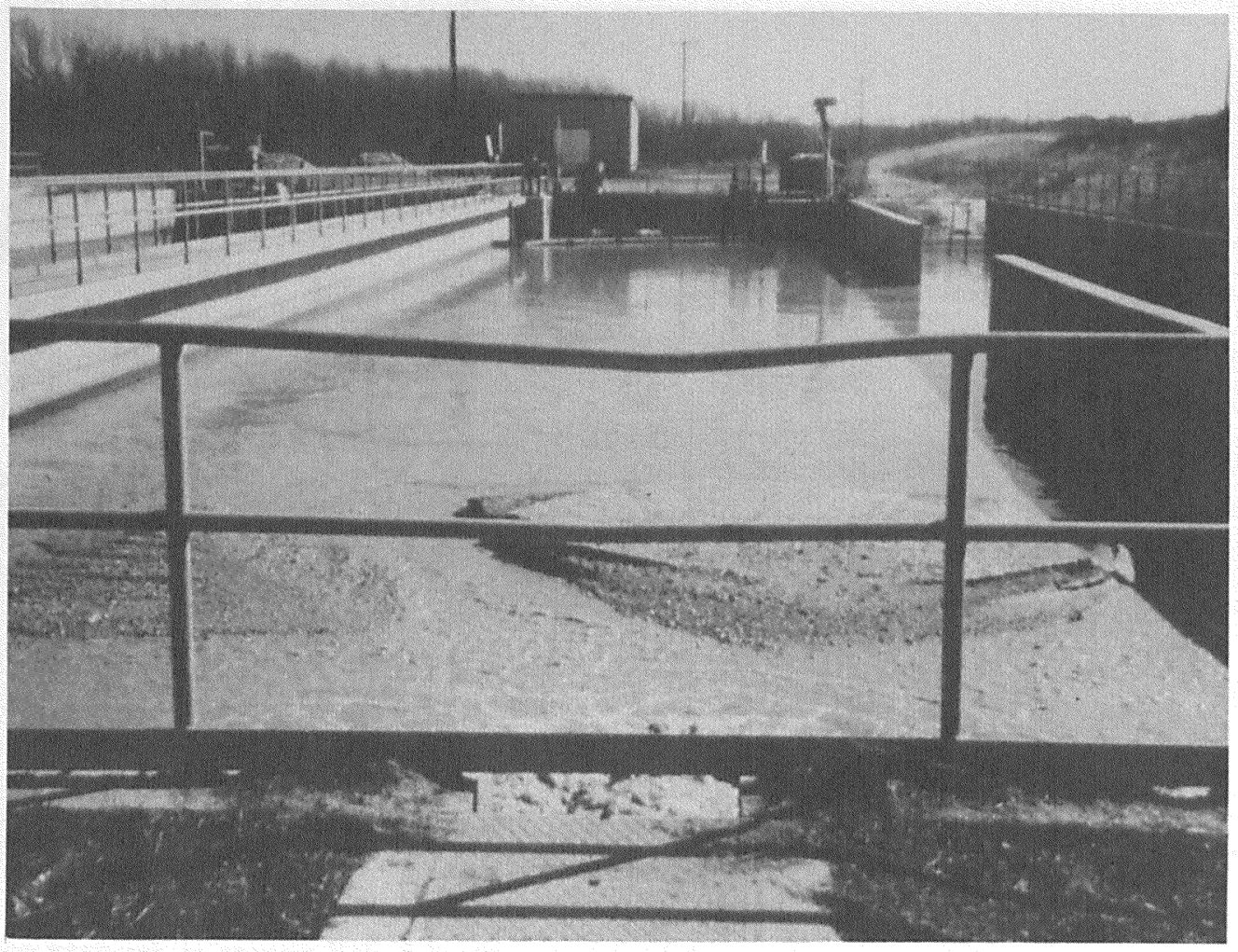

Figure 2. Primary sedimentation basin, Fort Hood, Texas

The objective of the secondary treatment system is to polish the primary system effluent to the degree necessary for process water recycle. The two secondary treatment schemes are intermittent sand filtration and treatment lagoons.

The sand filtration scheme involves the construction of an equalization basin and a sand filter field. The equalization basin dampens flow changes from the primary system. The sand filter field consists of a wastewater distribution system situated above a sand/gravel bed together mounted above a subsurface water collection system. Wastewater is distributed at the sand/ gravel bed surface, collected after filtration through the sand bed, and deposited in a make-up water supply basin for reuse in the CVWF. Treatment lagoons are not the recommended standard and currently require permission by Headquarters, U.S. Army Corps of Engineers, for construction. However, they are currently seen in operation at various installations. Generally, a lagoon system will consist of an equalization basin or lagoon followed by a polishing lagoon. The polishing lagoon is generally designed for the minimum of a 14-day retention time. Further deposition of sediments from vehicle wash operations is expected within the lagoon system, and design life requirements include this storage capacity. Water from the treatment lagoons enters the make-up water supply basin for reuse in the CVWF.

Additionally, water from the primary treatment system may be directly discharged into the sanitary sewer or surface drainage channel. However, 
these options are generally considered unlikely due to either municipal wastewater treatment mass loading constraints or National Pollutant Discharge Elimination System (NPDES) permitting requirements. Also, discharging to a wastewater treatment system outside the CVWF eliminates recycle as an option.

\section{Operational Problems}

Operational problems associated with the wastewater primary and secondary treatment systems are the focus of this discussion. These problems were observed at Fort Hood, Texas, and/or Fort Polk, Louisiana, during recent inspections. Operational problems associated with the user interface with the CVWF cleaning process are beyond the scope of this review.

\section{Problem 1 (Fort Hood)}

Statement. The CVWF primary treatment system appeared to be inadequate for the solids loading witnessed by the system.

Discussion. CVWF-solids loading rates appeared to be higher-than the 1-year design life between cleaning. Operators at Fort Hood indicated that each settling basin required clean out two to three times a year and that each cleaning generated approximately $500 \mathrm{cu} \mathrm{yd}^{1}$ of material. Additionally, the sediment loads were high enough that sediment deposits were actually breaking the surface of the primary sedimentation basin (see Figure 3 ). The result was a far higher apparent surface-loading rate in the settling basin than the original design. As a result, higher amounts of suspended solids carried over into the secondary treatment system.

\section{Problem 2 (Fort Hood)}

Statement. CVWF primary treatment systems require improved sediment dewatering techniques.

Discussion. Observers from WES and CERL found that dewatering of sediments at Fort Hood was dependent primarily on evaporation. After a quiescent period, a clear-water layer was decanted into the effluent trough using a sluice gate. Decantation brought the water level down to approximately $6 \mathrm{ft}$. From that point on, evaporation was used to remove the moisture from the approximately $500 \mathrm{cu}$ yd of sediment remaining in the basin. A sediment dewatering drain was available; however, an operator indicated that attempts to operate the drain lead to a complete discharge of sediment into the

1 A table of factors for converting non-SI units of measurement to SI units is presented on page vii. 


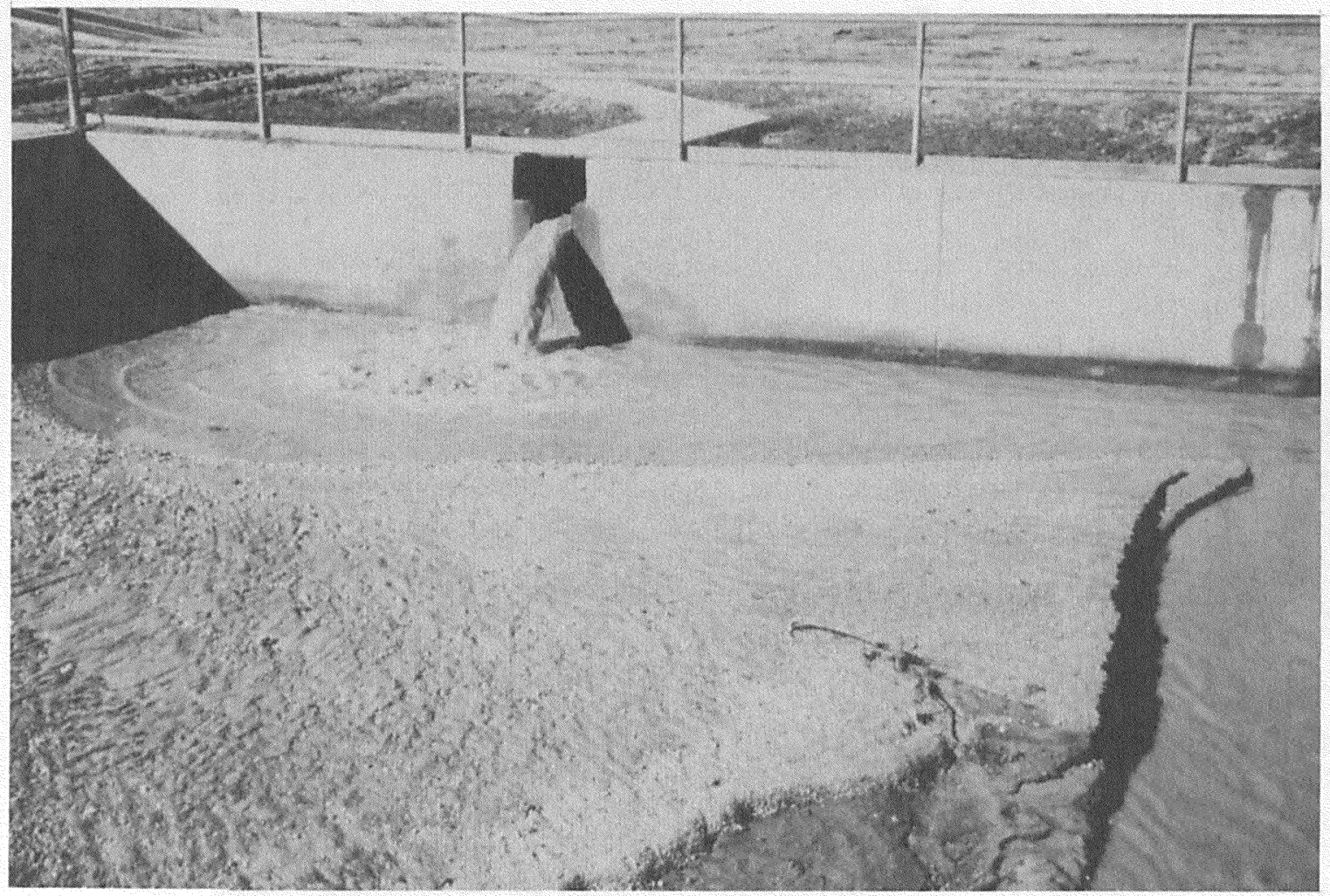

Figure 3. Sediment overload and short circuiting, primary sedimentation basin, Fort Hood, Texas

pump sumps and subsequent clogging of the pumps. As a result, operators removed the sediments after evaporation had removed enough water to allow the sediment some structural stability. The sediment was then front-end loaded into dump trucks, with a significant loss of material back into the basin during loading (see Figure 4).

A second CVWF with a single basin design had no bottom drains or sluice gates. As a result, essentially all the water had to be pumped to the degree possible and then evaporated as a method of solids dewatering before physical removal.

The major impacts in both cases were increased down time and reduced efficiency.

\section{Problem 3 (Fort Hood)}

Statement. Short circuiting of the silts and clays through the equalization basin of the secondary treatment system occurred.

Discussion. The equalization basin of the secondary treatment system had the influent and effluent points in essentially the same one-third of the basin. As a result, the sediment was deposited in only one-third of the sedimentation 


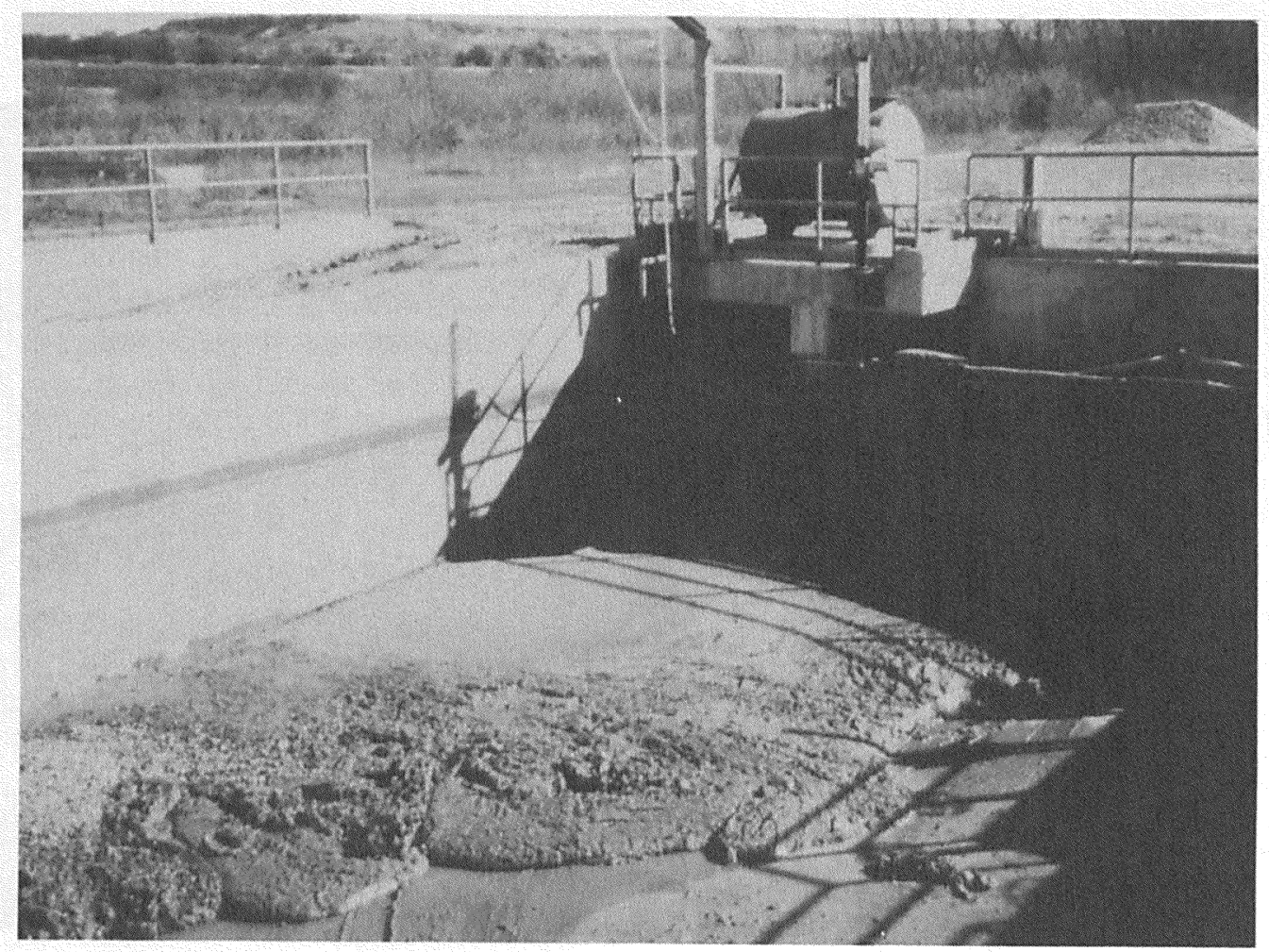

Figure 4. Fine solid residuals, primary sedimentation basin, Fort Hood, Texas

basin instead of equally distributed over the basin floor (see Figure 5). Also, higher than design suspended solids concentration was probably entering the primary sedimentation basin. Additionally, the overall system retention time was reduced.

\section{Problem 4 (Fort Hood and Fort Polk)}

Statement. Sedimentation basin cleaning must be addressed.

Discussion. Sedimentation basins must be cleaned as they near the end of their design life due to sediment accumulation. If deposition rates are higher than anticipated, design life may be reduced. Investigating available options is important to extend the life of the sedimentation basins and/or lower cleaning costs. Options may include complete removal and disposal of the basin liner and replacement of the liner, or dredging of the basins using nonintrusive techniques that will reduce the chance of puncturing the liner (see Figure 6).

\section{Problem 5 (Fort Hood and Fort Polk)}

Statement. Appropriate sampling methods must be employed in determining ultimate sediment disposal requirements. 


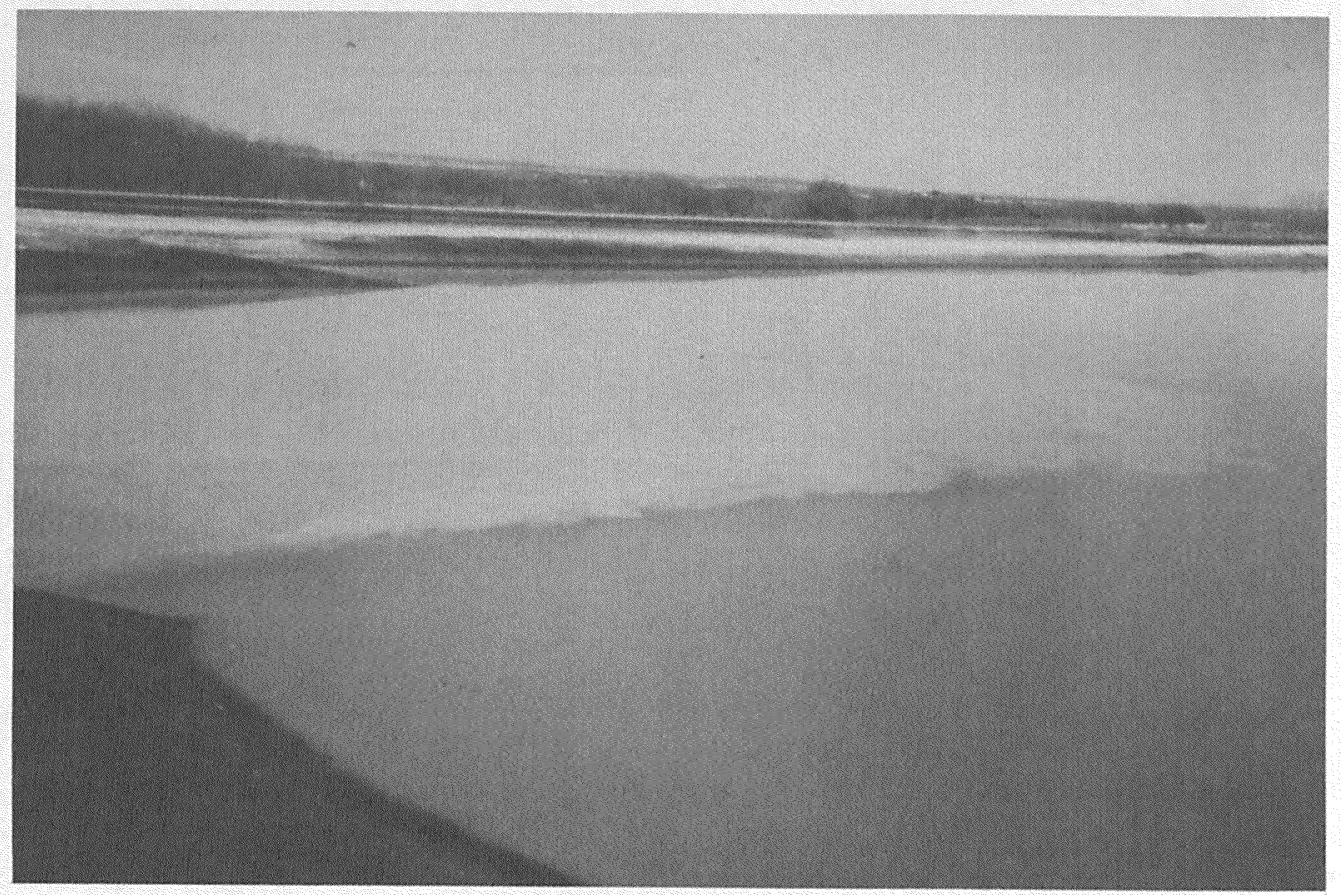

Figure 5. Short circuiting, secondary sedimentation basin, Fort Hood, Texas

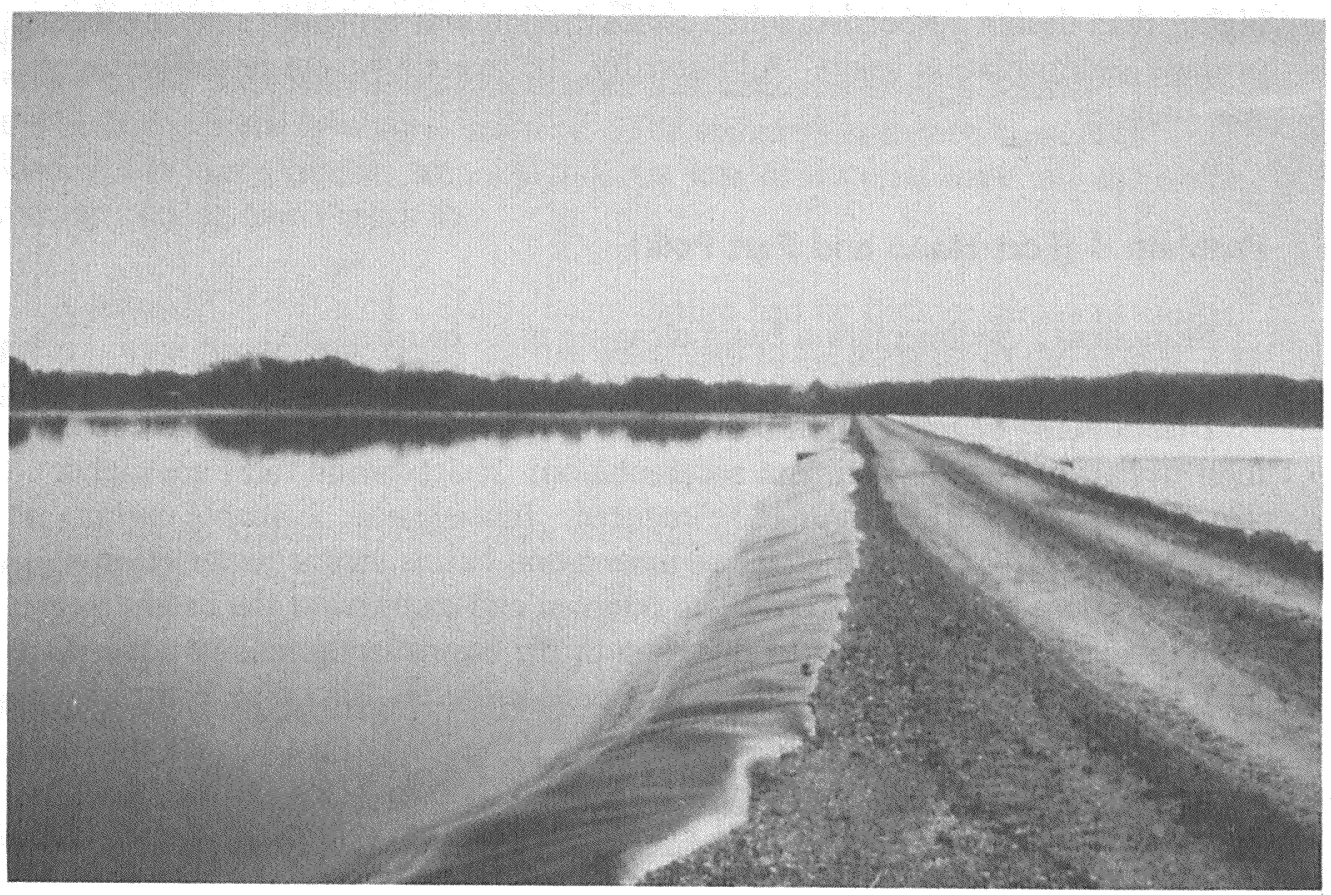

Figure 6. Secondary sedimentation basins, Fort Hood, Texas 
Discussion. Ultimate disposal of the sediments must be based primarily on analysis of the sludge material from the basin or lagoon in question and applicable environmental regulations. Installation environmental coordinators must also understand the importance of adequate sampling methods so that regulators will approve of the method of disposal proposed. A CVWF residual treatment scheme in one State may be quite different from a CVWF residual treatment scheme in another State, both in cost and procedure, because of the local regulatory requirements. Federal regulations are the baseline for State regulations; however, many States impose more stringent requirements.

Consequently, residue disposal will remain a site specific issue. 


\section{Technologies}

\section{Regulatory Requirements}

Review of Federal and State regulations regarding handling and disposal of contaminated residuals will be necessary for each individual CVWF location. A review of the regulatory framework for dredged material was conducted because there are some similarities between dredged material and CVWF solid residuals. However, solids removed from CVWFs are not defined as dredged material, thus these regulations would not in general apply (USACE/USEPA) (1992). The major exception would be the case of materials removed from the settling or dewatering basins and proposed for disposal as fill in waters of the United States, including wetlands.

Chapter 6 of Army Regulation 200-1 addresses solid waste and hazardous waste management at Army installations and requires installations and tenants to be aware of and comply with all applicable Federal, State, and local laws and regulations. Controlled management and waste minimization are identified as necessary objectives of Army solid and hazardous management programs.

\section{Testing}

Testing requirements are dictated by State and Federal regulations and can be determined by a review of regulations and contact with individual State and Federal agencies. The USEPA publication Test Methods for Evaluating Solid Waste: Physical/Chemical Methods (SW-846) addresses representative sampling and other testing requirements (USEPA 1986). This publication is currently in the third edition and is updated periodically. It is available from the Government Printing Office, NTIS (National Technology Information Service) and other publication service agencies. Sediments should be fully characterized to determine physical and chemical characteristics that will determine appropriate handling, treatment, and disposal alternatives. 


\section{Sampling}

Sediment sampling requirements will be driven by regulatory requirements for testing prior to disposal. Sampling for characterization and chemical analysis will typically require small-sample volumes. These samples must be representative of the overall sediment and must be handled and preserved in keeping with testing requirements. CFR 40 guidance on representative sampling can be found in Chapter 9 of SW-846 (USEPA 1986). Sampling for testing of treatment systems will require more material, the amount being dependent upon the type and scale of equipment being tested.

Materials in the settling basins or dewatering basins will be similar to dredged sediments in confined disposal facilities (CDFs), with high water contents, possibly above the liquid limit of the material. The material in the settling basins may be nonhomogeneous due to a layering effect resulting from washing operations of differing vehicle types or after operation in different soils; it is typically distributed nonhomogeneously along the length of the basin. The sampling design should, therefore, consider the need to acquire a representative composite of the total volume of material to be disposed.

Because the material in the basins may be composed of layers with differing characteristics, sampling from the full thickness of material will be required. Surface samples will not be adequate. Since the thickness of the materials in the basins will only be a few feet, a push tube sample will likely be adequate in most cases. There are several types used in soil and sediment sampling. Two examples are described below:

\section{Wildco hand corer}

The Wildco hand corer is a hand-driven corer with a metal shaft and semiconical tip and seal (flutter valve) for sample retention. Eggshell inserts are available that minimize sample loss as the corer is retrieved. Clear acrylic liner tubes are also available. The Wildco corer was designed for sampling sediments in shallow water. Fluid sediments may be easily displaced by the corer, making sample collection difficult. Hard, compacted sediments may be difficult to penetrate with the sampler. The standard shaft is roughly 3 in. in diameter and 24 in. long. The sampler can be modified with longer shafts and plastic tips.

\section{Lexan tube samplers}

Lexan tube samplers operate on the same principle as Wildco hand corers. The tubes are made of Lexan, which requires a protective tip or sleeve while the tube is being driven into the sediment. The tubes are driven by hand until refusal. They are then driven several inches more with a driver to plug the end and prevent sample loss on retrieval. A vacuum can be connected to the top of the sampler. The tube is capped while still submerged. 
Samples obtained with tube samplers will be extruded and stored as required to preserve the contaminants of interest. Sectioning can be facilitated by freezing if this is not contradictory to other requirements. Chain-ofcustody procedures will be followed.

A sampling plan should be developed to ensure that a sufficient number of samples are obtained to adequately characterize the sediment. Factors to be considered include the following (adapted from Mudroch and MacKnight 1991):

a. Purpose of sampling.

b. Study objectives.

c. Available data.

d. Physical site constraints.

e. Volume or area to be sampled.

f. Available funds.

The purpose of sampling CVWF sediments is to characterize and analyze the sediments. Objectives of a thorough characterization include determining contaminant distribution and evaluating appropriate materials handling and treatment technologies for the particle distribution present. Certain grain sizes are-most suited to-bioassays -(Mudroch and MacKnight 1991).

Determination of contaminant distribution requires samples of all particle sizes present. Data available on contaminant distributions within CVWF sedimentation basins indicate that full depth samples will be required, distributed over the width and length of the basins because of irregularities in contaminant distributions observed in previous analysis.

Physical limitations pertaining to sediment sampling may include the highly fluid nature of the fine sediments contained within the basins, which may make both sample retrieval and access difficult. Samples may have to be obtained before all the surface water is drained off, while a small boat or platform could still be floated to obtain access to interior areas of the basins. The area to be sampled is not extremely large, and typically the sediments are deposited in predictable patterns. Typical sediment contaminant distributions can be used to determine an appropriate sampling grid.

The number of samples to be analyzed will be determined by available funds and the expected course of action should contaminants be found. The most economic approach is to initially analyze only those samples that are most likely to be contaminated (typically the fines) if the presence of any contamination would initiate a specified response (e.g., disposal in a toxic waste landfill or solidification and landfilling) for all sediment in the basin. 
More extensive analysis may be justified if treatment or beneficial uses are to be considered for some or all of the sediment and a more thorough characterization is necessary.

\section{Physical/Chemical Treatments}

A review of treatment and disposal methods for contaminated and uncontaminated soils and sediments was taken from the available literature. There is considerable expertise available on standard management practices in handling and dewatering of dredged material. Also, extensive research has been completed or is ongoing in the treatment of contaminated soils and sediments. Limited performance data are available concerning treatment of contaminated dredged material. Some treatment technologies developed for contaminated soils may be applicable to contaminated dredged material. A recent cooperative effort between WES, USACE Districts, and the USEPA evaluated some of these technologies and treatment/management selection strategies (Averett et al. 1990). This guidance document was reviewed for applicability to CVWF solids management. Also, a review of the literature and analysis of field data indicates that there are two possible approaches to CVWF solids management:

Approach 1: Dewatering of sediment within the CVWF settling basin, followed by treatment and disposal after the sediment is removed from the basin.

Approach 2: Removal of slurried material from the basin, followed by dewatering, treatment, and disposal technologies.

Treatment and disposal are determined by the physical characteristics of the contaminated materials, the nature and concentration of contaminants present, and technical, budgetary, and regulatory constraints. The same treatment and disposal technologies should be applicable to CVWF solids (whether sediments are dewatered before or after being removed from the basin) unless significant differences in the contaminants and material characteristics result from different dewatering or handling techniques.

Other treatment considerations are apparent from the literature. Coarse and fine fractions of contaminated sediment is considered desirable because contaminants tend to associate with the fine-particle fraction of a sediment. In theory, the coarse fraction can usually be disposed without treatment, while fine sediments can require further treatment before disposal. In practice, perfect separation of coarse/fine fractions and clean/dirty fractions does not occur. Particle-size analysis and chemical analysis of samples from primary sedimentation basins at Aberdeen Proving Ground; Fort Campbell, Fort Carson, Fort Hood, Fort Stewart, and Fort Bragg demonstrate some inconsistencies. In some cases, fine particles were deposited near the influent end of the basin where primarily coarse-particle deposits were expected. Although some differences in contaminant concentrations could be measured from 
influent to effluent end of the basins (and coarse-to-fine sediment distribution), there was no clear indication that adequate separation of particle sizes was occurring within the basins to support the "coarse is clean" assumption. Representative sampling and testing of all sediments removed from the basins may be necessary to determine ultimate treatment and disposal requirements.

Analysis of the field data supplied by CERL, indicates that particle distribution in the CVWF primary sedimentation basins ranges from roughly $0.1 \mu \mathrm{m}$ to $6.5 \mathrm{~mm}$. Samples excluding the coarse fraction (away from the influent end of the basin) range from 0.1 to $300 \mu \mathrm{m}$, with consistently greater than 90 percent passing the 200 sieve $(75 \mu \mathrm{m})$. One hydrometer analysis indicated 70 to 80 percent smaller than $36 \mu \mathrm{m}$. Colloids are defined as particles less than 0.01 to $10 \mu \mathrm{m}$ in size. In several cases, 10 percent was smaller than 0.1 to $0.3 \mu \mathrm{m}$; in one case, 30 percent was colloidal.

The solids content by weight of fine CVWF sludge following decantation and a period of surface evaporation is estimated to be approximately 30 to 40 percent.

From analysis of the field data it can be seen that liquid/solid separation, solid/solid separation (classification), and sediment contaminant treatment technologies are of principal interest to this effort.

\section{Dewatering}

Dewatering is the common term for liquid/solid separation directed at producing a dry solid residual. The types of water associated with solid particles include the following: bulk or free water, micropore water, colloidally bound water, and chemisorbed water. Bulk water, which is intermingled with the solids but not bound to them, can be removed by conventional mechanical dewatering processes. Micropore water is located in pores and capillaries of the solids and is difficult to remove. Some micropore water can be removed by high-pressure processes. Colloidally bound and chemisorbed water are bound by surface forces or chemical bonds. Colloidally bound water and chemisorbed water are not removed by any conventional mechanical dewatering processes. Processes such as electrokinetics, acoustic, and electro-acoustic dewatering address removal of bound water, but are presently in developmental stages (Ensminger 1986; Muralidhara, Senapati, and Beard 1986; and Lockhart 1986). Thermal technologies address drying the sediment by causing a phase change in water contained in the sediments, as distinct from dewatering technologies that remove water without inducing a phase change. Thermal technologies require high-energy inputs and are not considered to be economically feasible or necessary for this application.

The water distribution of a typical colloidal suspension given by Muralidhara, Senapati, and Beard (1986) illustrates the limitations of conventional mechanical dewatering processes for this type of suspension: 
- Bulk water

- Micropore water

- Colloidal water

- Chemisorbed water
40 percent

40 percent

10 percent

10 percent

Handling and dewatering of fine sediments is problematic in CVWF operation. Coarse materials are typically excavated and removed shortly after surface water is removed. Fine materials require weeks to months to dewater sufficiently to be minimally workable with heavy equipment (30- to 40-percent solids content, by weight, estimated). The focus of this section is directed principally toward dewatering techniques for fine materials.

Dahlstrom (1986) gives a concise summary of the necessary analysis sequence for a liquid/solid separation problem. Some of the elements of the analysis sequence are listed in Table 1 , some of which may not be applicable to CVWF solids. The information in Table 1 represents a quick paper study that could be performed for each sediment to be dewatered to facilitate technology selection.

Dewatering technologies applied to dredged material can provide some insight into the management of CVWF solids. Important differences between dredged material management and CVWF solids management should be noted. Most significant is a difference in scale. A CDF may be designed to contain thousands of cubic yards of dredged material. Primary CVWF sedimentation basins at Fort Hood produce approximately 1,000 to 1,500 cu yd of material per year. Larger sedimentation ponds, such as those used for primary settling at Fort Story and secondary settling at Fort Hood, contain more material but still significantly less than the amount of dredged material contained in a CDF. Operational scale differences are significant in that equipment and methods utilized in dredged material handling may not be readily adapted to CVWF solids management.

CDF operations serve a dual function: dredged material dewatering and long-term storage. Sedimentation basins through which CVWF wash water flows provide primary or secondary separation of solids and water and shortterm storage incidental to the operation. At some point, operation is suspended to allow removal of solids from the basins and disposal elsewhere. Operational maintenance varies from one facility to another, and basin cleanout may or may not occur as a regular maintenance function (see CVWF Operational Procedures/Problems in Chapter 1).

Operational objectives of a CDF are different from those of a CVWF sedimentation basin. Consolidation of dredged material is desirable from the standpoint of increasing available storage within the CDF. Improving engineering properties of the dredged material for beneficial uses may also be an objective (Johnson et al. 1977). Consolidation of sediment in a CVWF sedimentation basin is desirable principally to facilitate rehandling (removal and disposal) of the material. Acceptable time frames for dewatering and consolidation of dredged material (months to years) will be significantly 





longer than for a CVWF sedimentation basin, where continued operation is dependent upon expedient removal of solids from the basin.

Demonstrated dewatering and densification techniques for dredged material are listed below, along with processes having potential application to CVWF solids (Averett et al. 1990 and Johnson et al. 1977):

a. Primary settling.

b. Surface drainage.

c. Subsurface drainage.

d. Solar evaporation.

e. Progressive trenching.

f. Wick drains/vertical drainage panels.

g. Surcharge loading.

h. Vertical sand drains.

$i$. Chemical additives.

j. Filtration.

(1) Belt filter press.

(2) Vacuum filtration.

(3) Chamber filtration.

(4) Centrifugal filtration.

(5) Crossflow filtration.

$k$. Gravity thickening.

l. Centrifugation.

m. Hydrocyclones.

Other potentially applicable techniques include vegetative desiccation and thinlift placement. Figure 7 from Muralidhara, Senapati, and Beard (1986) citing Shafick (1981) gives the applicable particle-size ranges and potential solids concentrations produced for several of the above-mentioned processes. 


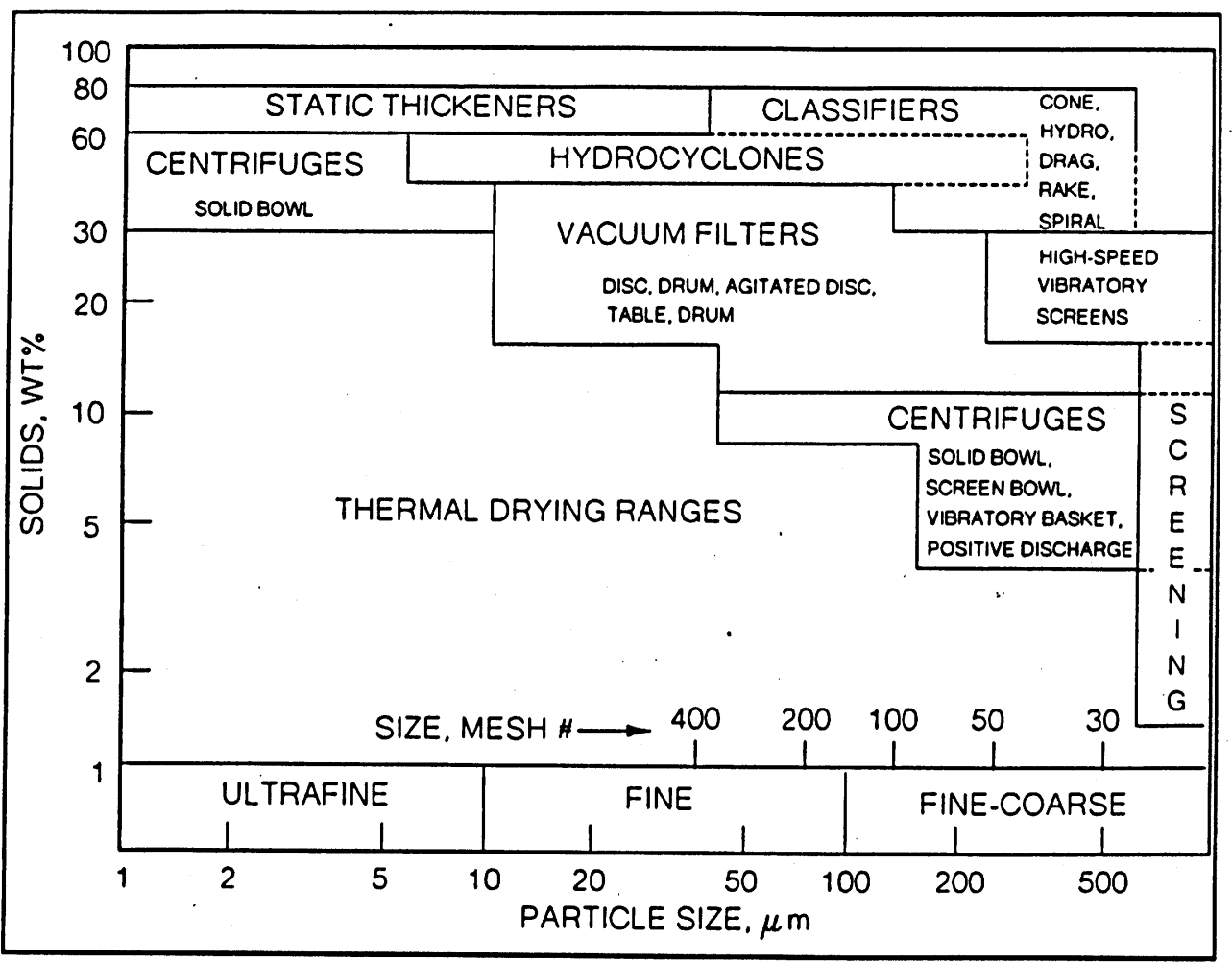

Figure 7. Particle size and process solids concentrations (from Muralidhara, Senapati, Beard 1986)

Effective dewatering techniques are needed for CVWF solids management. A discussion of dewatering technologies follows.

Primary settling. Primary settling is the deposition by gravity of settleable solids from a liquid-waste stream. Primary settling is the most widely used dewatering technology applied to dredged material and is the technology in use for initial water/solid separation at CVWFs visited. 'Wastewater from the CVWF is directed to the inlet of a settling basin. Settling basins are designed based on overflow velocity, defined as volumetric flow divided by plan area of the basin. A given overflow velocity will allow particles of a prescribed diameter to settle out before the wastewater leaves the basin through the outlet. Particles too small to settle, including colloids that will not settle without chemical coagulation, are carried out in the effluent from the basin.

Primary settling achieves the initial gross liquid/solid separation, but sediments still contain high amounts of water that must drain by gravity after surface water is drained off. Fine sediments have low permeabilities, and gravity drainage can take a long time. For this reason, primary settling is sometimes combined with adjunct processes such as subsurface drainage. Another alternative, which is not mentioned in the literature but which may merit consideration, is some type of body feed to the influent of the sedimentation basin for the purpose of increasing the permeability of the fine deposits. 
Body feeds are utilized in conjunction with filtration to enhance flow through the filter cake and have the characteristics of high permeability and rigidity. Subsurface drainage, filtration, and body feeds are discussed further in the following text.

Surface drainage. Surface drainage of standing water is the first step in dewatering sediments deposited in a sedimentation basin (Bartos 1977). Surface drainage is achieved by the use of weirs and other adjustable watercontrol structures in order to release surface water while retaining solids.

Adequate surface drainage removes remaining standing water, prevents reinfiltration due to ponding from rain or consolidation of foundation materials, and exposes the sediment to the air. A quiescent period before surface drainage is initiated may be necessary to ensure sufficient time for deposition of all settleable particles. Once adequate surface drainage is achieved, more aggressive dewatering techniques can be employed.

Subsurface drainage. Subsurface drainage, or underdrainage, can be achieved by providing a permeable base and perforated drainage pipes in the foundation material of the sedimentation basin. Drainage pipes could not be installed in existing concrete sedimentation basins unless provision was made for heavy equipment to work over them to remove deposited sediment. A sacrificial sand or gravel layer could potentially enhance dewatering of the fine sediments that accumulate in the lower one-half to two-thirds of the basin, but has not yet been tried. A perforated drainage pipe, wrapped in geotextile and placed in a gravel bed, runs the full length of the concrete sedimentation basins at Fort Hood. This has been insufficient to promote adequate drainage of the basin. Fouling of the gravel and geotextile with fines has been an operational problem and must also be considered with an underdrainage bed. An underdrainage system would probably require provision for backwashing or be sacrificed when the basin is emptied.

Sand beds are a potentially viable alternative for dewatering outside of the sedimentation basin. An underdrainage system could be incorporated in a modified CDF. With somewhat coarser sediments, the Japanese have recently implemented an underdrainage system utilizing nonwoven polypropylene fabric over a bed of drain pipes. ${ }^{1}$ Vertical panels covered with the same fabric and placed at intervals within the basin provide an enhanced drainage path to the drain bed. Maximum dewatering time for a 2-m-deep basin was 5 months. Minimum dewatering time was 1 month. Sediments were removed from the basin by mechanical means when the water content in percent of dry weight divided by the liquid limit was less than 1.0 .

Solar evaporation. Solar evaporation is a suitable dewatering technique in arid climates where sufficient storage is available to allow adequate drying times. Wet sediments or slurries can be allowed to dry naturally in a lined

1 M. Nakamura. (1994). "Dewatering of dredged material from Fushiki Toyama Port by bottom dewatering system," unpublished report. 
pond or lagoon. Solar evaporation will also enhance the performance of sanddrying beds.

Progressive trenching. Trenches are dug around the perimeter of a containment area, and in parallel or radial patterns throughout the disposal area, down to the existing depth of the crust. As the crust thickens, the trenches are reworked and deepened. The principal function of the trenches is to provide good surface drainage so that rainfall does not reinfiltrate the sediment and to increase natural evaporation by exposing progressively greater surface area to the air. Trenching can be done with a backhoe when a thin crust (approximately 6 in.) forms on the top surface of the sediment. Crust formation can take several weeks to several months after drying begins. The time frame involved here would preclude progressive trenching as an in-basin dewatering technology. Underdrainage could further enhance this dewatering method, and progressive trenching could be useful as an out-of-basin dewatering method.

Wick drains. Wick drains consist of rigid, pleated polymeric strips wrapped in a geotextile fabric. Wicks are placed vertically in a grid pattern to promote radial and vertical drainage of pore water upward along the wicks. A sand surcharge can be added to increase pore pressures and speed consolidation (Averett et al. 1990).

Wick drains are presently in use at Craney Island disposal area and have produced consolidation of several feet over a period of approximately 9 months, with wicks placed to depths over $100 \mathrm{ft}$.

Vertical drainage panels consisting of pipe frames covered with nonwoven polypropylene fabric have been demonstrated for dewatering dredged sediment approximately $2 \mathrm{~m}$ deep. ${ }^{1}$ The panels are utilized in conjunction with a bottom drainage system of perforated pipes covered with the same fabric.

Wick drains and vertical drainage panels are not expected to be a viable in-basin dewatering technology for CVWF operations because the time required for consolidation to occur is too long for efficient operation of the system. The volume of sediments is small and would be more efficiently managed by out-of-basin dewatering. Wick drains and vertical drainage panels may be viable dewatering devices for out-of-basin dewatering, permitting reuse of a single small containment basin constructed for the purpose.

Surcharge loading. Surcharge loading, a densification technique, is the practice of loading coarse-grained material over dredged material to increase effective stresses and enhance drainage of pore water. The primary objective of densification techniques is to reduce the volume of the dredged material and increase storage capacity of the disposal area. Surcharge loading is sometimes

1 M. Nakamura. (1994). "Dewatering of dredged material from Fushiki Toyama Port by bottom dewatering system," unpublished report. 
employed in conjunction with wick drains. Surcharge loading is not considered applicable to CVWF solids management, particularly since separation of coarse (clean) and contaminated (fine) sediments is desired.

Vertical sand drains. Vertical sand drains consist of sand columns placed or injected into saturated solids. They connect with an underdrainage layer or intermediate horizontal drainage layer and accelerate consolidation by providing a preferential flow path to the drainage layer. This reduces the drainage path length (Bishop and Vaughan 1972). Placement may involve boring, requiring a minimum bearing capacity of the sediments. Injection, or preplacement, may be effective for very fluid sediments.

Fouling with fines is an operational problem, particularly with high-flow velocities. Smearing of the drains during installation and because of consolidation settlement may reduce effectiveness. Discontinuities in the drains also reduce effectiveness. Horizontal spacing of vertical drains is an important design parameter and will be a determining factor in the economic feasibility of the use of vertical sand drains.

Chemical additives. Chemical additives to a suspension cause particles to agglomerate and enhance settling characteristics. Coagulants or flocculants can be added to the influent to the sedimentation basin. The potential benefit of flocculants is highly dependent upon the nature of the slurry, the chemical composition of the flocculant, and the dosage. Selection of flocculant for dewatering is determined by the nature of the material to be dewatered and solid-liquid separation method to be employed (Moudgil and Shah 1986). For example, for dewatering of clays, a high-density floc is desirable. Table 2 is adapted from Moudgil and Shah (1986).

\section{Table 2}

Floc Characteristics for Specific Applications

\begin{tabular}{||l|l||}
\hline \hline Method of Separation & Desired Floc Properties/Mechanism \\
\hline \hline Filtration & $\begin{array}{l}\text { Porous, strong, permeable flocs } \\
\text { (High dosages required for complete flocculation) } \\
\text { Patch-charge neutralization mechanism }\end{array}$ \\
\hline Sedimentation & $\begin{array}{l}\text { Dense, strong, large, regular in shape } \\
\text { Bridging mechanism }\end{array}$ \\
\hline Centrifugation & $\begin{array}{l}\text { Strong, dense, large flocs } \\
\text { Bridging mechanism }\end{array}$ \\
\hline Floc flotation & Low-density, strong, narrow size distribution \\
\hline
\end{tabular}

Flocculants act to neutralize charges between suspended particles (patchcharge neutralization) or bridge the electrical double layer of the particles (bridging). Suspended particles can also be removed from solution by becoming enmeshed with cross-linked polymer chains (network flocculation).

Studies indicate that materials may have a higher water content following flocculation because of intrafloc water that is not readily removed unless 
flocculation is followed by a filtration process. The study referenced found pressure filtration (approximately $50 \mathrm{psi}$ ) to be effective (Cheng and Chiang 1990) in removing intrafloc water. Filter cake moisture contents of approximately $0.17 \mathrm{~kg} / \mathrm{kg}$ (dry) were achieved.

Studies on dredged material indicate that flocculants will expedite the initial settling of clay particles; with the addition of underdrains, surface drainage and evaporation, solids contents of 50 percent are achievable. The length of time to attain this solids content was found to require about 10 months for an 18-ft dredged-material layer on sand bed, but was not specified for smaller layers. Studies on phosphatic clays and bauxite residues resulted in solids contents from 28 to 35 percent with flocculation alone.

Flocculants may accelerate the sedimentation process and could be expected to produce a clearer effluent from the primary sedimentation basins, thereby reducing solids loading to the secondary settling basins. However, with high solids content in the feed stream, flocculation can inhibit settling. Selection of flocculant and determination of dosage would require bench-scale testing for the specific application. Flocculation will not likely produce a more workable sludge than that presently obtained in the primary sedimentation basins by sedimentation alone; the sludge produced may be more difficult to dewater because of trapped intrafloc water. However, with sufficient land area available to further dewater the sludge by passive means (by land application or on sand beds), the benefits of flocculation to the efficiency of the overall operation is a viable consideration.

Filtration. The object of filtration is to (a) produce a clear filtrate, or (b) separate and capture solids from a slurry for reuse, treatment, or disposal, or (c) both.

Filter feed can be (a) principally liquid, with low concentration of suspended solids, or (b) a sludge or slurry, with high solids content.

Production of a dry, workable solid residual (cake) is the principal objective of CVWF operation. Cake quality varies with the type of filter utilized. Pierson (1990) indicates driest cakes are produced by the following:

a. Filter presses.

b. Vacuum filters.

c. Pressure leaf filters.

d. Centrifugal filters.

e. Spinning leaf filters.

f. Cartridge filters. 


\section{g. Compression filters.}

Several characteristics distinguish filter types (Pierson 1990; and Loff 1990). In particular, these are as follows:

a. Filtration through a filter medium or through a filter cake.

b. Gravity, vacuum, pressure, or centrifugal driving force.

c. Surface or depth filtration.

Depth filtration includes deep sand filters and some cartridge filters. Typically, deep sand filters must be periodically backwashed, or the upper layers must be sacrificed as they become occluded with solids. Because of the high solids content, deep sand filters are not considered to be suitable for dewatering CVWF residuals.

Cartridge filters are available in depth and surface filtration types and offer particle retention from 0.5 to $50 \mu \mathrm{m}$, depending upon the media. Depth-type cartridges cannot be cleaned to recover solids, and in general cartridge filters are limited in application to suspensions of less than 0.01-percent solids by volume (Svarovsky 1990a). Because of these limitations, cartridge filters are considered unsuitable for CVWF residuals dewatering.

Surface filters are employed with feed solids concentrations above 1 percent.

Blinding is an operational problem in filtration, particularly when filtering slurries containing fine particles. Blinding can occur in the filter cake or in the filter support or media and occurs to some degree in all filters. Blinding in the cake can be rectified with chemical pretreatment (flocculation) or varying the pressure differential (Pierson 1990). Blinding in the filter support can be addressed by utilizing a support larger than the smallest fraction to be filtered and allowing the coarser material to form a filter bed, which is the fundamental principle behind cake filtration. Cake filtration requires an adequate fraction of coarse material in the feed stream from which to build a cake. Filtrate is recycled until a sufficient cake accumulates to capture fines and give an acceptably clear filtrate (or, conversely, an acceptably high solids capture). Filter precoats and/or body feeds, using a filter aid, are sometimes used to form a filter cake. Filter aids have the characteristics of permeability, pore size, and rigidity (Smith 1990). Diatomite, perlite, and cellulose are examples of filter aids and are used alone or in combination.

Cake washing as an incidental filter function is an additional consideration and may be desirable as a treatment process. Belt filter presses give a wellwashed cake but consume large amounts of water in the process. Vacuum filters may be more desirable in performing this function (Pierson 1990). 
A discussion of specific filtration processes follows.

a. Belt filter press. Belt filter presses employ a three-stage operation:

(1) Slurry containing from 1 to 40 percent solids is conditioned with either addition of flocculant or by processing through a thickening drum section.

(2) Gravity drainage of free water.

(3) Compression between a press belt and filter belt.

Solids contents of 50 to 60 percent by weight were achieved with river sediments. Belt filter press equipment is available on a large commercial scale (Averett et al. 1990).

b. Vacuum filtration. Vacuum filters comprise the majority of continuous filters presently employed in industry (Dahlstrom 1986). Drum filters and disc filters form filter cake against gravity; continuous belt horizontal, horizontal scroll, and tilting pan filters form filter cake with gravity. Vacuum drum filtration is a continuous process in which a drum is partially submerged in a slurry, and a vacuum is applied to the inside of the drum, causing flow through the drum. A solids cake forms on the outside of the filter and is scraped off and removed. String discharge and continuous belt drum filters are well suited to filtration of materials that tend to blind other filters, such as clays and colloids (Dahlstrom 1986).

Vacuum filtration has been tested on dredged material with an initial solids content of 15 to 23 percent. Filter cake with solids content above 43 percent was achieved. Capital and operating costs were very high for a large-scale operation, and the technology was determined to be uneconomical for treatment of dredged material (Averett et al. 1990). An economic analysis would be required to determine the feasibility for an operation on the scale of the CVWF facilities.

c. Chamber filtration. Chamber filtration is a pressure filtration process utilizing rigid vertical plates covered with a filter media. Chamber filtration is a semicontinuous process. Slurry is pumped through the filter until sufficient cake forms to restrict flow. Pumping is stopped and filter media cleared for the next cycle. Plate and frame filtration is a proven technology capable of producing filter cake with solids concentrations in excess of 50 percent (Averett et al. 1990).

d. Centrifugal filtration. The principal object of centrifugal filtration is to produce dewatered solids, as opposed to clear filtrate. Centrifugal filters consist of a rotating basket with a filter medium (Zeitsch 1990). Surfactants can be utilized to reduce the final moisture content of the solids. Centrifugal filters are continuous or batch operation, depending 
upon the type selected. Centrifuge type is selected based on the intrinsic permeability of the material to be dewatered. Permeabilities below $0.02 \times 10^{-10} \mathrm{~m}^{4} / \mathrm{N}^{*} \mathrm{~s}$ are too low for centrifugal filtration, but may be suitable for centrifugal sedimentation (see Centrifugation). Permeability above $20 \times 10^{-10} \mathrm{~m}^{4} / \mathrm{N}^{*} \mathrm{~s}$ is required for continuously fed pusher centrifuges. Permeabilities between these two values require the use of batch-fed equipment, such as three-column and peeler centrifuges (Zeitsch 1990). Feed rates and water content of filtered solids were not given in this reference.

e. Crossflow filtration. Influent flow is tangential to the filter media in crossflow filtration (Svarovsky 1990). The induced shear along the filter face prevents a heavy buildup of solids on the filter media and subsequent blinding. High filtration rates are possible. Svarosvky (1990) does not indicate an optimum feed solids concentration or ultimate water content of separated solids, but does indicate that in some cases water contents are lower than with conventional pressure filtration. Given the nature of most CVWF solids, this process could have applicability to residuals dewatering.

Gravity thickening. Gravity thickening is a variation on primary settling, in which the primary objective is not a clarified effluent but a thickened underflow. Gravity thickening utilizes a specially designed circular vessel to dissipate influent velocity and allow for the sludge to settle. This technology has not been applied to dredged material slurries (Averett et al. 1990) and would seem to offer little advantage as a follow-on process to the primary settling presently in use at CVWF facilities.

Centrifugation. Centrifuge separation utilizes a rigid vessel that is rotated rapidly, producing forces in excess of gravity, to enhance and accelerate liquid/solid separation. Centrifugal separators can be divided into three categories: centrifugal filters, sedimentation centrifuges, and combined centrifugal filters/sedimentation centrifuges (Alt 1986). Centrifugal filtration is discussed in the preceding section on filtration technologies.

Centrifugal dewatering is applicable over a particle size range from gravel down to roughly $10 \mu \mathrm{m}$ and has been demonstrated in municipal sludge dewatering operations (Averett et al. 1990). According to Alt (1986), centrifuges suitable for fine-particle dewatering include tubular-sedimentation centrifuges, disc-nozzle centrifuges, and self-cleaning disc centrifuges. These units operate in batch, continuous, and semicontinuous modes respectively. Under lowflow conditions, a scroll-type centrifuge could also be applicable to the particle distribution of CVWF residuals and gives continuous operation and discharge (Svarovsky 1990).

Tubular sedimentation centrifuges are low capacity; as a solids cake accumulates in the bowl, efficiency drops. They are limited in application to suspensions of less than 1-percent solids (Svarovsky 1990b). The disc centrifuges are high capacity (Alt 1986). Svarovsky (1990b) gives the relationship 
between cut size and feed rate for the nozzle-discharge disc centrifuge; the cut size increases as feed concentration and flow rate increase (Figure 8). Feed concentration for the self-cleaning or solids-ejecting-type disc centrifuge is limited to 2 to 6 percent (Svarovsky 1990b). Scroll-type centrifuges can separate particles less than $50 \mu \mathrm{m}$ in size at 2- to 50 -percent solids by volume in the feed. Residual moisture increases with solids feed rate, and pilot tests would be needed to determine if an adequate flow rate could be maintained and still achieve the desired particle separation and moisture content (see. Figures 9 and 10).



Figure 8. Dependence of cut size $X_{50}$ on feed concentration and flow rate for nozzle-discharge disc centrifuge (from Svarovsky 1990b)

The slurry solids concentration of CVWF primary sedimentation basins is estimated to range from 5 to 40 percent immediately after decanting and following a period of evaporation, respectively. The latter value exceeds the feed values for centrifugal separators and would require dilution.

According to Alt (1986), the tubular sedimentation and disc centrifuges result in low to moderate residual moisture. Averett et al. (1990) indicate that solids concentrations of 15 to 40 percent can be achieved with a solid-bowl centrifuge, while disc centrifuges achieve lower solids concentrations. Scrolltype centrifuges give roughly 30-percent moisture content for $100-\mu \mathrm{m}$ particles at low-solid feed rates (Svarovsky 1990b). The maximum solids concentration that can be achieved with centrifugal dewatering is no higher than can be obtained by decanting and evaporation. The chief advantage of centrifugal separation is in shorter dewatering times. Figure 11 correlates flow rate and particle size to equipment alternatives (Svarovsky 1990b, citing Lavanchy, Keith, and Beams 1964). 


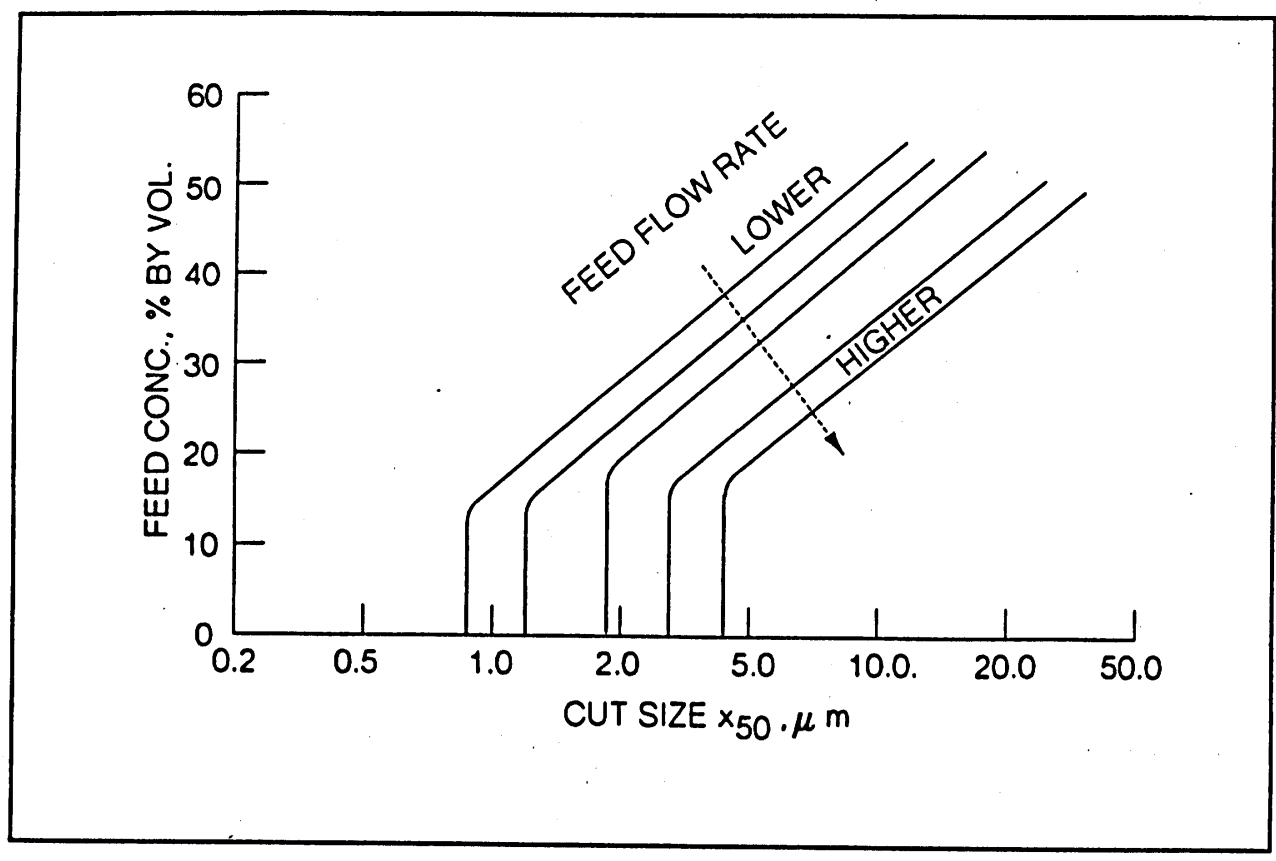

Figure 9. Effect of feed concentration and flow rate on cut size $X_{50}$ for scroll-type centrifuge (from Svarovsky 1990b)

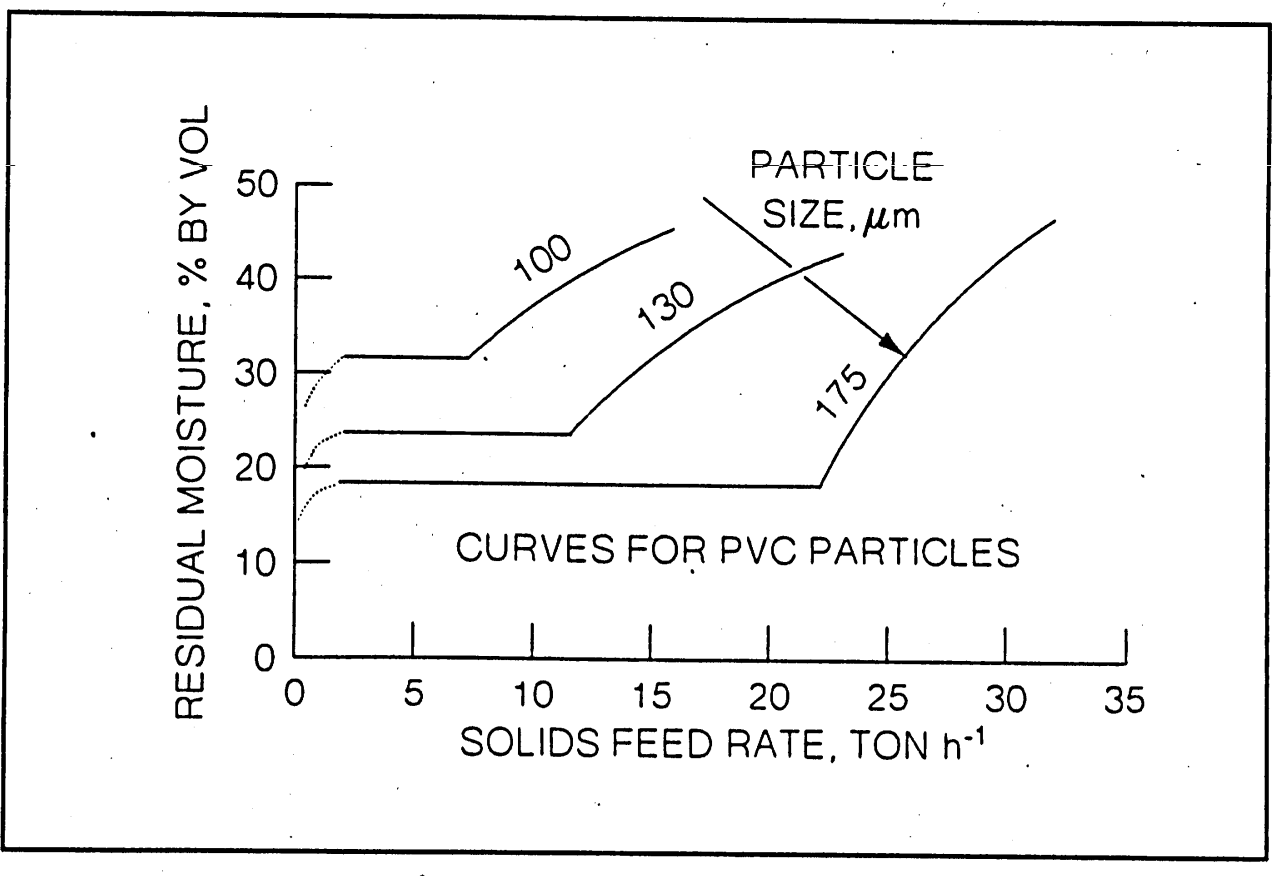

Figure 10. Scroll-type centrifuge dewatering performance declines at critical feed rate (from Svarovsky 1990b) 


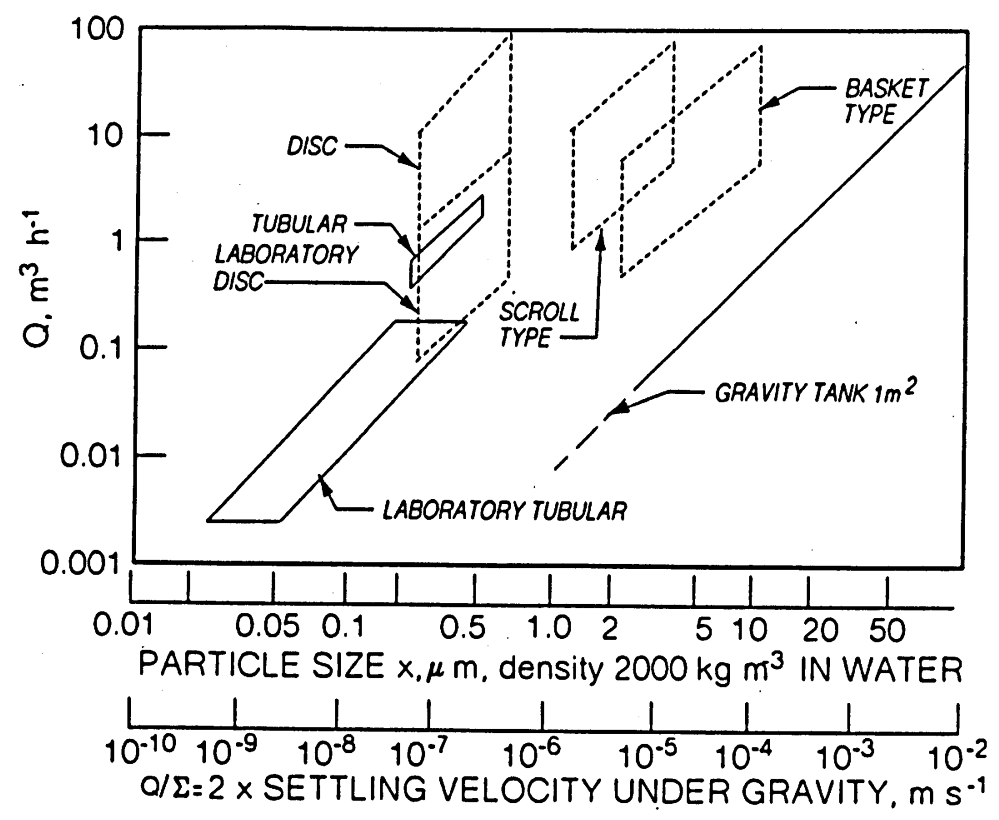

Figure 11. Performance of various centrifugal sedimentation equipment (from Svarovsky 1990b)

Hydrocyclones. Slurry is fed into a conical vessel, forming a vortex. Coarser materials flow out the underfiow outiet, while fine materials are carried by a countercurrent out the overflow outlet. Hydrocyclones have no moving parts and are available in a wide range of capacities. Fineness of separation appears to be proportional to capacity; smaller capacity hydrocyclones achieve finer separation (Averett et al. 1990). Narrow-angle hydrocyclones are most efficient for fine-particle recovery, having a smaller cut size than wide-angle cyclones. Maximum underflow concentration, approximately 50 to 60 percent, is achieved by throttling the underflow orifice and is a function of the materials (Svarovsky 1990b). A consequence is that clarity of overflow is sacrificed, since more material is subsequently carried out with the overflow.

Since CVWF wash water is recycled through the facility, carryover of fines could be addressed by secondary settling of the overflow in the existing secondary settling basins, possibly with the addition of flocculants. Presumably, any contamination present in the overflow is also already present in the secondary settling basins.

Hydrocyclones were evaluated for densifying dredged material slurries (Tiederman and Reischman 1973). The technique was reasonably successful in pilot tests for classifying solids and separating coarse and fine fractions. Concentration of low-solids content clay slurries was also fairly successful, 
but performance was poor on the dredged material. High-solids content slurries appeared to inhibit performance.

Other important performance variables are operating pressure drop and feed concentration (Svarovsky 1990b). Up to 5 or 6 bars, increasing pressure drop correlates to increased separation efficiency. Conversely, efficiency of separation decreases with increasing feed concentrations. Slurries with a solids concentration greater than 30 percent, high specific gravity, or high clay content are unsuitable for treatment separation using hydrocyclones (Averett et al. 1990).

Vegetative desiccation. Vegetation can significantly diminish soil moisture contents because of water uptake and transpiration. The type of vegetation, depth of rooting relative to depth of sediment, and density will influence the effectiveness (Bartos 1977). Shading from excessively dense vegetation could slow evaporation from the surface of the dredged material, and the presence of vegetation can present problems in subsequent material placement. Vegetative drying would not likely be compatible with progressive trenching techniques, but could be an effective technology for slurries placed in a permanent or semipermanent containment area. An additional benefit of this dewatering method is the potential for metals/organics uptake by the plants.

Thin-lift placement. Thin-lift placement refers to deposition of dredged material in thin layers, which can shorten dewatering times significantly. The concept could be adapted to sedimentation basins by cleaning the basins more frequently, so the sediment deposits are more shallow and the flow path downward through the material is shortened. Placement of a sacrificial drainage layer on the bottom of the sedimentation basin could potentially further shorten dewatering times within the sedimentation basin. Lifts of $0.3 \mathrm{~m}$ are considered most desirable for evaporative drying with no intervention. Lifts $1 \mathrm{~m}$ in depth may require up to a 2-year drying period (Bartos 1977). Studies of evaporative drying of dredged material indicate that the rate of evaporation from the dredged material was the same as the pan evaporation for a given locality for the first few days of drying. Thereafter, evaporation dropped to approximately 50 percent over a period of 90 days.

Selection of dewatering technologies for CVWF solids management. Table 3 summarizes the dewatering technologies presented here.

The most desirable dewatering technologies for CVWF management will be low maintenance, low cost processes, or process trains, capable of producing residuals-solids contents high enough to facilitate handling and disposal of the CVWF sludge. Percent solids by weight is a common delimiter for defining the separation between fluid residuals and residuals ranging in handling characteristics from plastic to brittle. The percent solids at which a particular residual material can be handled by mechanical means will be dependent upon the nature and size distribution of particles and must be determined on a caseby-case basis. For fine-grained sediments passing the 200 sieve, but larger than colloidal, a water content falling somewhere between the liquid limit and 


\begin{tabular}{|c|c|c|c|c|}
\hline \multicolumn{5}{|c|}{$\begin{array}{l}\text { Table } 3 \\
\text { Summary of Dewatering Technologies } \\
\end{array}$} \\
\hline Technology & Type of Process & Feed Particle-Size Range & Foed Solids Concentration & Solids Concentration Achieved \\
\hline Primary Settling & Gravity settling & $\begin{array}{l}\text { All - colloids require addition } \\
\text { of flocculants }\end{array}$ & $\begin{array}{l}\text { All - hindered settling may } \\
\text { occur with high solids in feed }\end{array}$ & $\begin{array}{l}\text { Present operations: } \\
5 \text { to } 10 \% \text { surface water removed } \\
30 \text { to } 40 \% \text { after evaporation }\end{array}$ \\
\hline Surface Drainage & Adjunct to settling processes & All & All & N/A - shortens dewatering times \\
\hline Subsurface Drainage & Adjunct to settling processes & $\begin{array}{l}\text { All - fines may clog drainage } \\
\text { layer }\end{array}$ & All & Varies with material and over time \\
\hline Solar Evaporation & Evaporative drying & All & All & Varies with material and over time \\
\hline $\begin{array}{l}\text { Progressive } \\
\text { Trenching }\end{array}$ & Adjunct to settling processes & All & All & Varies with material and over time \\
\hline Wick Drains & Adjunct to settling processes & All & All & Varies with material and over time \\
\hline Vertical Sand Drains & Adjunct to settling processes & Ali & All & Unspecified \\
\hline Chemical Additives & $\begin{array}{l}\text { Adjunct to settling, filtration, } \\
\text { centrifugation }\end{array}$ & Fine materials & $\begin{array}{l}\text { Hindered settling can result if } \\
\text { used with high solids } \\
\text { concentration in feed }\end{array}$ & Varies with process \\
\hline Belt Filter Press & Filtration & Unspecified & 1 to $40 \%$ (dry weight) & 50 to $60 \%$ solids \\
\hline Vacuum Filtration & Filtration & Unspecified & 15 to $23 \%$ (dry weight) & $>43 \%$ \\
\hline & & & & ICont \\
\hline te: $N / A=$ & & & & \\
\hline
\end{tabular}




\begin{tabular}{|c|c|c|c|c|}
\hline Technology & Type of Process & Feed Particle-Size Range & Feed Solids Concentration & Solids Concentration Achieved \\
\hline Chamber Filtration & Filtration & Unspecified & Unspecified & $>50 \%$ \\
\hline Centrifugal Filtration & Filtration & $\begin{array}{l}\text { Specified by permeability and } \\
\text { type of centrifuge }\end{array}$ & Unspecified & Unspecified \\
\hline Crossflow Filtration & Filtration & Unspecified & Unspecified & Exceeds filter press in some cases \\
\hline Gravity Thickening & Sedimentation & $\begin{array}{l}\text { All - fines may impede } \\
\text { thickening }\end{array}$ & Unspecified & Unspecified. \\
\hline $\begin{array}{l}\text { Scroll-Type } \\
\text { Centrifuge }\end{array}$ & Sedimentation & $\begin{array}{l}\text { Will accept }<50-\mu \mathrm{m} \text { feed, top } \\
\text { end unspecified }\end{array}$ & 2 to $50 \%$ (dry weight) & $30 \%$ - varies with feed material \\
\hline $\begin{array}{l}\text { Solid-Bowl } \\
\text { Centrifuge }\end{array}$ & Sedimentation & Unspecified & Unspecified & 15 to $40 \%$ \\
\hline Disc-Type Centrifuge & Sedimentation & Unspecified & Unspecified & < solid bowl centrifuge \\
\hline Hydrocyclones & Classification & Unspecified & $<30 \%$ (dry weight) & 40 to $60 \%$ underflow \\
\hline $\begin{array}{l}\text { Vegetative } \\
\text { Desiccation }\end{array}$ & & $\begin{array}{l}\text { All sediments that will } \\
\text { support vegetation }\end{array}$ & All & Varies with conditions and over time \\
\hline
\end{tabular}


approximately 1.8 times the liquid limit of the material will define the upper limit of a workable range. For disposal purposes, regulatory requirements specify what must be treated as a solid waste or liquid waste based on the paint filter test.

In the case of CVWF solids at Fort Hood, fine residuals contain an estimated 30- to 40-percent solids by weight following decantation and a period of evaporation. This solids content is minimally sufficient to permit handling by mechanical means. Solids contents above 40 percent would appear to be desirable for mechanical handling, with sludges at lower solids contents better handled by pumping from the sedimentation basins and dewatering by follow-on processes.

Dewatering technologies applied to sediments within the basin must be effective over a relatively short time interval to permit rapid basin cleanout and return to operation. Unit processes applied to sludges pumped from the basins have more flexibility.

Of the types of dewatering technologies available, some generalizations can be made. Gravitational classifiers are most suitable to 80 -mesh (roughly $200 \mu \mathrm{m}$ ) and above separations. Hydroseparators are applicable to processing large volumes at 100 - to 200 -mesh (150 to $75 \mu \mathrm{m}$, respectively) separations with only moderate precision requirements. Hydrocyclones are applicable from 80 mesh down to $10 \mu \mathrm{m}$, and centrifuges are utilized for very fine separations (Dahlstrom 1986). Figure 12 gives particle sizes appropriate to certain types of separation equipment (Svarovsky 1990a).

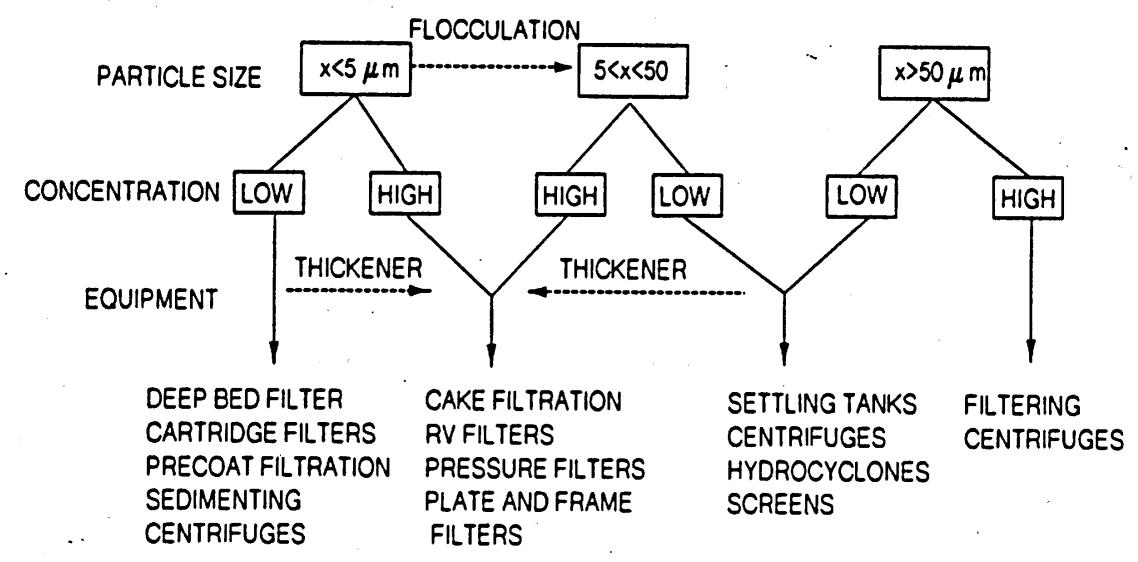

Figure 12. Particle size as a guide in selection of solid-liquid separation equipment (from Svarovsky 1990a) 
The technologies potentially most suitable to CVWF dewatering are rated in Table 4, on a scale of 1 to 5 , based on implementability (I), effectiveness $(E)$, cost $(C)$, and time $(T)$ required. $A(U)$ for effectiveness indicates no published data for that process. The time factor is weighted (X2) because of the need to dewater and remove sediments quickly. Out-of-basin technologies are ranked highly for this factor based on the sediments being removed quickly from the basin, rather than the actual time to implement the technology once the material is removed from the basin.

The rating procedure favors out-of-basin technologies because of the time factor. Simple, in-basin procedural modifications rank highest for implementability and cost. Effectiveness of these and all procedures considered would have to be tested at bench, pilot or field scale, as appropriate. Fieldscale testing is most reliable and is economically feasible if expensive equipment is not required, such as field testing of underdrainage layers, body feed, and thin lifts. Field testing of underdrainage layers, body feed, and thin lifts could be tried by temporary modification of operating procedures at nominal cost. More technologically intricate systems may be limited to bench- or pilot-scale testing prior to implementation.

\begin{tabular}{|l|l|l|l|l|l|l|l|l|l|l|l|l||}
\hline \multicolumn{10}{|l|}{$\begin{array}{l}\text { Table 4 } \\
\text { Dewatering Technology Rating }\end{array}$} \\
\hline \hline $\begin{array}{l}\text { In-Basin } \\
\text { Technologies }\end{array}$ & I & E & C & T (X2) & Overall & $\begin{array}{l}\text { Out-of-Basin } \\
\text { Technologies }\end{array}$ & I & E & C & T (X2) & Overall \\
\hline \hline Primary Settling & 5 & 2 & 5 & 2 & 3.5 & Belt Filter Press & 3 & 5 & 2 & 10 & 5.0 \\
\hline $\begin{array}{l}\text { Primary Settling + } \\
\text { Subsurface } \\
\text { Drainage }\end{array}$ & 4 & U & 4 & 6 & 4.67 & $\begin{array}{l}\text { Vacuum/Chamber } \\
\text { Filtration }\end{array}$ & 3 & 4 & 1 & 10 & 4.5 \\
\hline $\begin{array}{l}\text { Primary Settling + } \\
\text { Body Feed }\end{array}$ & 4 & U & 4 & 6 & 4.67 & Hydrocyclones & 3 & 4 & 3 & 10 & 5.0 \\
\hline Thin Lifts & 5 & U & 4 & 6 & 5.0 & $\begin{array}{l}\text { Underdrainage/Sand } \\
\text { Drying Beds }\end{array}$ & 4 & U & 4 & 10 & 6.0 \\
\hline & & & & & & Centrifuge & 3 & 3 & 2 & 10 & 4.5 \\
\hline
\end{tabular}

\section{Particle separation (classification)}

Separation of coarse and fine fractions of sediment can minimize the volume of sediment requiring treatment for contaminants. Contaminants are principally associated with fine-sediment particles. The natural distribution of sediments within the sedimentation basin facilitates the use of separate removal, treatment and disposal technologies.

Distribution of particles within sedimentation basins typically results in a concentration of coarse particles near the inlet of the structure and with fine particles settling more slowly and depositing near the outlet. Some small and colloidal particles are carried over in the effluent and necessitate secondary 
settling or other treatment. Both secondary settling and sand-bed filtration followed by secondary settling are in use at Fort Hood. Fort Polk relies on secondary settling alone. Secondary settling basins contain primarily fine sediments.

Particle-size analysis of sediments from primary sedimentation basins at several military facilities indicates a particle-size distribution that ranges generally from $6.5 \mathrm{~mm}$ to less than $0.0002 \mathrm{~mm}$.

Some fine particles are inevitably trapped by the coarse-sediment deposit, and some coarse particles are carried over into the fine sediments. Particle separation beyond what can be achieved in sedimentation basins becomes important when significant contaminant concentrations show up in the coarse materials due to the amount of entrapped fines, or when a particular treatment technology requires further particle classification.

Particle classification technologies suitable for application to contaminated dredged material included the following (Averett et al. 1990):

a. Flotation.

b. Grizzlies.

c. Hydraulic classifiers.

d. Hydrocyclones.

e. Impoundment basins.

f. Screening.

(1) Moving screens.

(2) Stationary screens.

g. Shaking table.

h. Spiral classifiers.

Impoundment basins are equivalent to the CVWF sedimentation basins currently in use. Impoundment basins, hydraulic classifiers, and hydrocyclones have been demonstrated on dredged material. The other technologies listed were evaluated in bench- and pilot-scale tests for potential application to treatment of contaminated dredged material on technology effectiveness, implementability, and cost.

Flotation. Flotation is a process in which fine particles are removed from suspension by attachment to air bubbles generated by rotary blades in a flotation device. The resulting froth is carried out in the overflow. Suspended 
particles can be chemically conditioned to cause them to be air-avid and water-repellent (Averett et al. 1990).

Flotation has been applied in a number of commercial industries, including various mining operations. Suitability to separation of CVWF sediments requires laboratory evaluation. Particles finer than roughly 50- to 65-mesh can potentially be removed by this process. Conceptually, treatment of a sludge requires agitation of the sludge to separate and suspend the fine particles (attrition) followed by the flotation process.

Grizzlies. Grizzlies are utilized for large-particle separation and are composed of parallel bars mounted in frames 1 to 5 in. apart. Units may be vibrating or fixed and can be arranged in series to achieve progressive separations (Averett et al. 1990).

One- to five-inch separation is too coarse to be of practical use for CVWF particle classification. However, an adaptation of this technology can potentially be applied to capture ordnance in CVWF influent.

Hydraulic classifiers. Hydraulic classifiers are most effective for classification of particles in the range of fine gravel to fine sand. They can be utilized in conjunction with spiral classifiers or hydrocyclones to remove finer particles, particularly particles smaller than 200 mesh (Averett et al. 1990). Upflow columns are hydraulic classifiers that effectively remove fines from coarser materials prior to other unit processes to further concentrate the contaminated materials.

Hydrocyclones. Hydrocyclone operation was described more fully under dewatering technologies, but it is principally a classification technology since loss of some fine solids is inherent in the operation. Flocculation cannot be used to increase recovery because of the high shear forces present during operation. The "cut" that can be achieved in classification ranges from roughly 2 to $400 \mu \mathrm{m}$, with smaller cut size associated with narrow-angle cyclones and larger cut size with wide-angle cyclones. The cut for a wideangle hydrocyclone would be sufficient to separate coarse CVWF residuals from fines for further treatment and disposal. Maximum underflow concentration is 45- to 60-percent solids by volume (Svarovsky 1990b).

Hydrocyclones in parallel permit more efficient, smaller units to handle high flows, while units in series increase overall recoveries. In general, hydrocyclones have low capital and operational costs and are small in size relative to other separation equipment.

Screening. Screening serves an extensive dewatering function in the mineral industry for materials ranging from 0.1 to $1.0 \mathrm{~mm}(100$ to $1,000 \mu \mathrm{m})$. CVWF fines are largely smaller than this (75 $\mu \mathrm{m}$ and below); thus, screening would principally be applicable for separation of coarse and fine fractions of residuals to facilitate treatment. However, dewatering of the coarse fractions can occur incidentally to the classification process, which can be useful for 
separating fines from a sacrificial sand bed or coarse body feed if these technologies were employed to enhance in-basin dewatering of fines.

a. Moving screens. Vibrating screens are most commonly used and can be arranged in series for progressively finer screening (Averett et al. 1990). Screening is best suitable for dry or slurried materials. Vibrating screens are most commonly used to separate material ranging from $1 / 8$ in. to 6 in. High-speed vibrating screens are available for separation of material ranging from 4 to 325 mesh. Abrasion and blinding of screens are operating problems.

b. Stationary screens. Wedge-bar screens and hydrosieves are stationary screens utilized to achieved particle separation by the tangential movement of slurry across the screen face. Wedge-bar screens do not remove all fines from the coarser material and would not be suitable for this application. Hydrosieves utilize pressurized water spray that breaks up clumps, keeps the screen clear, and removes fine-grained material from coarse-grained material (Averett et al. 1990). Sieve bends, a type of hydrosieve, have a capacity of 8 to $10 \mathrm{~m}^{3} /$ hour for minus 0.5 -mm coal slurry at 30 - to 50 -percent solids by weight. Stationary screens are sometimes used preceding moving screens to increase overall efficiency.

Shaking table. Shaking tables are comprised of a distribution box at one end of a sloping, channeled surface that is mechanically shaken to achieve particle separation as a slurry flows across the table (Averett et al. 1990). Shaking tables are most effective when preceded by a hydraulic classifier, such as an upflow column, to first remove fine particles (slimes).

Spiral classifiers. Spiral classifiers employ a continuously rotating screw to wash, dewater, and classify sand and gravels up to $3 / 8$ in. in diameter. Units that are designed to be mobile typically require only simple maintenance, and capacities of up to 950 tons/hour are possible (Averett et al. 1990). Fixed spirals are effective concentrators that can achieve a three-way split of materials of significantly different size and density (heavies, mids, and fines). Spiral classifiers can be preceded by hydraulic classifiers, such as an upflow column, to remove fine-grained materials.

Evaluation of classification technologies (solid/solid separation). A disadvantage of hydraulic classification technologies is that they may require the introduction of additional water in order to achieve particle separation. Fines hydraulically separated from coarse materials must then undergo further dewatering in addition to treatment for contaminants.

Final selection of a classification technology will be made based upon the cut size required as indicated by contaminant distribution among particle sizes and treatment technology operating parameters, flow rate and volume to be treated, and relative cost of those technologies meeting these performance requirements. 


\section{UXE removal}

Removal of ordnance that has been picked up in the mud on the undercarriage of military training vehicles may be a consideration for some CVWF operations. Since such ordnance would be limited in size, a classification technology such as screens or bar grating would probably be effective in separating ordnance from the waste stream before sediments are deposited in the sedimentation basins.

\section{Treatment of contaminants}

The specific contaminants found in CVWF solid residuals will vary according to the management practices of the facility. Petroleum hydrocarbons, heavy metals, oil and grease, and some ordnance have been found in some of these sediments. The type and level of contamination will determine whether or not the material is hazardous and what treatment or disposal technologies will be required. Without information on specific compounds present, the form, and the concentration, specific treatment recommendations are difficult to make. Some general discussion follows regarding potentially applicable technologies for petroleum hydrocarbons, heavy metal, and oil and grease contamination in CVWF solid residuals.

Treatment processes for contaminated CVWF solids will potentially generate solid, liquid, and vapor waste streams. Assuming the coarse sediments are clean from a regulatory standpoint, treatment can be confined to the fine sediments. Table 5 summarizes treatment technologies applicable to the three primary classes of contaminants found in CVWF sediments (USEPA 1993).

Cost ranges in 1994 for the treatment technologies described are reported to range from $\$ 50 /$ cubic yard to $\$ 1,350 /$ cubic yard. Biological treatment is generally the lowest cost alternative, followed by solidification/stabilization. Incineration is the most expensive technology. The remainder of the technologies fall roughly within a range of $\$ 110$ to $\$ 600 /$ cubic yard. Treatment costs remain one of the most difficult parameters to predict in a remediation effort and are dependent upon a number of variables including characteristics of the sediment, quantity of waste processed, nature and concentration of contaminants, location of the site, and available disposal alternatives for waste streams generated by the process. Other site-specific factors may also influence costs.

Some of the treatment technologies listed in Table 5 have not been demonstrated at full scale on contaminated sediments but have documented effectiveness in other applications in bench- and pilot-scale trials. Because many contaminated sediment treatment processes are emerging technologies, benchor pilot-scale testing for site-specific conditions is a requisite to technology selection. 


\begin{tabular}{|c|c|c|c|c|c|}
\hline \multicolumn{6}{|c|}{$\begin{array}{l}\text { Table } 5 \\
\text { Treatment Technologies for CVWF Sediments }\end{array}$} \\
\hline $\begin{array}{l}\text { Treatment } \\
\text { Technology } \\
\end{array}$ & Particle Size Requirements & Water/Solid Requirements & Petroleum Hydrocarbons & Heavy Metals & Oil and Grease \\
\hline $\begin{array}{l}\text { Solvent } \\
\text { Extraction } \\
\end{array}$ & $<1 / 4$ in. & $\begin{array}{l}\text { Most processes require } \\
>20 \% \text { solids }\end{array}$ & Effective & Not effective & $<40 \%$ oily organics \\
\hline Soil Washing & $\begin{array}{l}0.063 \text { to } 2 \mathrm{~mm} \text { affect removal } \\
\text { from wash fluid } \\
\text { Fines require further treatment, } \\
\text { remove oversize material }\end{array}$ & Unspecified & Potential & Potential if soluble & Unlikely \\
\hline $\begin{array}{l}\text { Thermal } \\
\text { Desorption }\end{array}$ & $\begin{array}{l}>1 \text { to } 1.5 \text { in., high clay content } \\
\text { creates fugitive dust problems }\end{array}$ & $\begin{array}{l}20 \% \text { solids minimum, } 60 \% \\
\text { moisture content maximum }\end{array}$ & \begin{tabular}{|l|} 
Effective for volatile \\
components at up to \\
$10 \%$ \\
\end{tabular} & Unlikely & Unlikely \\
\hline $\begin{array}{l}\text { Solidification } \\
\text { /Stabilization }\end{array}$ & $\begin{array}{l}\text { Fines inhibit solidification } \\
\text { Not suited to large particles }\end{array}$ & $>15 \%$ solids & $\begin{array}{l}<20 \text { to } 45 \% \text { organics, } \\
<1 \% \text { by weight } \\
\text { semivolatile, } \\
\text { ineffective for volatiles } \\
\end{array}$ & $\begin{array}{l}\text { Effective for stabilized } \\
\text { metals }\end{array}$ & $<10 \%$ by weight \\
\hline Incineration & $\begin{array}{l}\text { Remove oversize material, } 1 \text { to } \\
2 \text { in., fines may carry through }\end{array}$ & $<50 \%$ moisture content & Effective & $\begin{array}{l}\text { Not effective, present in ash } \\
\text { or volatilized }\end{array}$ & \begin{tabular}{|l|}
$\begin{array}{l}\text { Not specified } \\
\text { Potential for low } \\
\text { concentrations }\end{array}$ \\
\end{tabular} \\
\hline $\begin{array}{l}\text { Land } \\
\text { Treatment }\end{array}$ & None & None & Effective & Not Effective & $\begin{array}{l}\text { Not specified } \\
\text { Potential for low } \\
\text { concentrations }\end{array}$ \\
\hline Oxidation & Not specified & Limited application to slurries & $\begin{array}{r}\text { Potential for low } \\
\text { concentrations } \\
\end{array}$ & Not effective & $\begin{array}{r}\text { Potential for low } \\
\text { concentrations } \\
\end{array}$ \\
\hline $\begin{array}{l}\text { Acid } \\
\text { Leaching }\end{array}$ & Not specified & Not specified & Not effective & Potential & Not effective \\
\hline $\begin{array}{l}\text { Biological } \\
\text { Treatment }\end{array}$ & $\begin{array}{l}\text { Composting mass } 0.3-\text { to } 5-\mathrm{cm} \\
\text { range } \\
\text { Fines may be incorporated in } \\
\text { this }\end{array}$ & $\begin{array}{l}40 \text { to } 65 \% \text { moisture } \\
\text { content - can be } \\
\text { adjusted with amendments }\end{array}$ & $\begin{array}{l}\text { Effective for many } \\
\text { compounds }\end{array}$ & Not effective & $\begin{array}{l}\text { Not specified } \\
\text { Potential for low } \\
\text { concentrations }\end{array}$ \\
\hline
\end{tabular}


Petroleum hydrocarbons. Treatment processes applicable to petroleumhydrocarbon-contaminated sediments include biodegradation, volatilization, land application, oxidation, extraction and incineration.

Biodegradation processes are discussed in the following section. Volatilization is the release of volatile contaminants from the soil by exposure to air or by thermal treatment and capture of the offgasses. Land application involves spreading of the contaminated sediment on the ground where volatile contaminants will be released to the air and other organics are available to and in contact with microbes contained in the soil. Oxidation is the chemical transformation of contaminants by the addition of an oxidizing agent. Oxidation is well suited to low concentrations of contaminants, since oxidants are nonspecific. Process control is critical to achieving complete oxidation, and intermediate compounds can form that are more mobile or more toxic than the parent compounds. Oxidation is reported to have limited application to slurries or sludges (Averett et al. 1990, citing Kiang and Metry 1982). Extraction involves removal of contaminants from sediment by the incorporation of a solvent. Contaminants associated with solid particles are dissolved into the solvent and removed from the soil by suitable dewatering technologies. Some solvents present environmental hazards, and residuals in the sediment may be a problem with fine materials in particular where dewatering is difficult to achieve. Incineration is the destruction of compounds by high thermal inputs. Metals and incompletely burned contaminants can be carried out in the offgasses. Incineration may not be effective for high-water content materials.

Land treatment is considered to be a viable alternative for CVWF sediments, subject to applicable regulatory limitations. Oxidation, extraction, and incineration require chemical and energy inputs and would probably not be justified when satisfactory treatment can be achieved with less aggressive technologies.

Heavy metals. Extraction, acid leaching, and solidification/stabilization are technologies applicable to treatment for metals contamination. Extraction was described under petroleum hydrocarbon treatment technologies. Acid leaching is similar to extraction. Acid is used to solubilize metals. The solids are then separated from the metals containing extract. The sediment may require an additional washing step, and the contaminated liquid waste stream must also be treated to precipitate the metals. The concentrated metals containing sludge must be disposed of as hazardous waste. Acid leaching is listed as an emerging technology in the Superfund Innovative Technology Evaluation (SITE) Demonstration Program as of November 1992 and has not been demonstrated at full scale on soil or sediments. Solidification/stabilization employs chemical pre-treatment to stabilize leachable metals and incorporates solidifying materials such as cement or fly ash and setting agents to produce a solid matrix with high structural integrity. Properly solidified and stabilized wastes can be disposed in conventional landfills, potentially reducing disposal costs, although the overall volume of waste is increased. 
Oil and grease. Oil and grease contamination are not specifically addressed in treatment technology summaries. Oil and grease are organic in nature, however, and should be amenable to treatments for other organic contaminants provided concentrations are not high enough to be inhibitory to the treatment process. Bench- or pilot-scale testing would be required to determine effectiveness for oil and grease removal for certain treatment processes.

Biological treatment of CVWF residuals. Biological treatment of CVWF residuals beyond direct land application at sites visited is not a component of current operations. The reason for this is that land application is often an appropriate and generally cost-effective disposal method in cases where State and Federal regulations allow. However, installation environmental coordinators, CVWF managers, and CVWF operators should remain aware that the changing nature of the material deposited and the transient regulatory environment require continued assessment of treatment technology. If CVWF residuals are assessed as special or hazardous waste as may happen in the future or if current operations are inadequate, then biological treatment beyond direct land application has special value.

Bioremediation, as it relates to the common contaminants found in residuals from CVWF, is defined as biological processes that through degradation, adsorption, or detoxification reduce a risk to human health or the environment posed by particular contaminants. Given the nature of CVWF residuals, the contaminants of particular concern are polycyclic aromatic compounds associated with fuels and solvents. The scientific literature suggests that these organic compounds are amenable to biological degradation. As early as the late 1970s, it was reported that biodegradation occurred when petroleum products entered the environment (Atlas 1977; Bartha and Atlas 1977; Colwell and Walker 1977). However, chemical structure greatly influences biodegradability (Atlas 1975), and the rate of degradation is dependent on the number of alkanes, isoalkanes, cycloaromatics, and aromatics (Blumer and Sass 1972). The idea that degradability is a function of molecular design continues to be supported by more recent work performed in the field as indicated in Table 6 . Table 6 is an abbreviated list of more recent research. In sediments, a review of the literature by Chang, Hult, and Noben (1987) not only affirmed the degradation by native microbial consortia, but asserted that degradation rates were lowered by both reduced temperature and nutrient limitations. In soils, the influence of temperature and nutrient availability has been similarly noted (Hahn and Loehr 1992). Consequently, it is reasonable to approach bioremediation of organic-contaminated CVWF residuals with some confidence.

The development of an approach to biological treatment of CVWF residuals will generally require a four-step approach. This approach includes a thorough characterization of the residual, confirmation of treatability, design of a treatment scheme, and implementation. While this approach is almost intuitive for the environmental engineer, the need for full characterization and confirmation of treatability cannot be overemphasized. 


\begin{tabular}{|c|c|c|}
\hline \multicolumn{3}{|c|}{$\begin{array}{l}\text { Table } 6 \\
\text { Reported Hydrocarbon Degradation Rates }\end{array}$} \\
\hline Contaminant & Biodegradability Indicated & Source \\
\hline Diesel Fuel & Yes & Wang and Bartha 1990 \\
\hline Jet Fuel & Yes & Wang and Bartha 1990 \\
\hline $\begin{array}{l}\text { Heating Oil } \\
\text { Two Ring } \\
\text { Aromatics }\end{array}$ & $\begin{array}{l}\text { Yes } \\
\text { Yes } \\
\left(t^{1 / 2}=2 \text { days }\right)\end{array}$ & $\begin{array}{l}\text { Wang and Bartha } 1990 \\
\text { Park et al. } 1990\end{array}$ \\
\hline $\begin{array}{l}\text { Three Ring } \\
\text { Aromatic } \\
\end{array}$ & $\begin{array}{l}\text { Variable } \\
\left(\mathrm{t}^{1 / 2}=16 \text { to } 50 \text { days }\right)\end{array}$ & Park et al. 1990 \\
\hline $\begin{array}{l}\text { More than } \\
\text { Three Ring }\end{array}$ & $\begin{array}{l}\text { Difficult } \\
\left(t^{1 / 2}>150 \text { days }\right)\end{array}$ & Park et al. 1990 \\
\hline
\end{tabular}

CVWF residual characterization must be broad. Besides a determination of the contaminant level, essential items of information includes total volumes, structure, bulk density, native $\mathrm{pH}$, clay content, clay type, cation exchange capacity, and organic matter content. A determination should be made regarding the time of year the treatment train will operate and the associated geographic location. Following characterization, treatability confirmation is required.

At first glance, there appear to be many approaches to bioremediation; however, three broad categories encompass most of the bioremediation processes appropriate to CVWF residual treatment. These three approaches are land application, in-vessel treatment, and composting.

Land application is the application of degradable contaminant to surface or the subsurface injection of degradable organic contaminant into the soil. To be effective, the contaminant organic material will be degraded by native microbial bacteria, given the availability of appropriate nutrients. Favorable economics is a principal advantage to land application; however, there are some drawbacks. These drawbacks include a lack of system control and a risk of irrevocable effect.

In-vessel systems are systems in which, as the name implies, biodegradation of the contaminant is made to occur in some type of tank or vessel. In the case of CVWF residuals, a slurry can be made of the contaminated material, and nutrients will be applied within an agitated or aerated tank. In-vessel systems have an advantage in that system control is high. For example, samples can be taken during system operation to ensure system performance; nutrients can be metered directly into the treatment system; and operating parameters can be changed to effect an operational change. Drawbacks to in-vessel systems are that capital costs are comparatively high, and operators generally need to be well trained.

The final system approach, composting, may hold particular promise for CVWF residual management. Composting is an adiabatic and aerobic process 
where microorganisms convert organic compounds into stabilized materials within a solid organic matrix system. Unique to compost operations is their exothermic nature. This attribute has been used by the municipal wastewater treatment industry for 15 years as a dewatering technique, and dewatering of residues is a major need in CVWF operations (as witnessed at Fort Hood). Further, there remains the bioremediation aspect of the composting.

During the past two decades, composting has become an increasingly important process in the environmental cleanup. Until the last 10 years, composting was considered primarily as a municipal sludge dewatering and treatment method. Presently, composting is becoming a leading bioremediation technology. The reasons for the change is that compost operations allow for a system control above direct land application, and, in general, capital costs are comparable with in-vessel costs; but the finished product, cured compost, often is a more desirable end product. Drawbacks remain, however. Because of its active biological nature, composting may require more attention on the part of the operator than direct land application; system control is not as direct as with in-vessel systems.

Specific literature citings which indicate the applicability of composting to residual and soils contaminated with hydrocarbons are widespread (Snell Environment Group 1982; Hogan et al. 1989; Yusuf 1991; Adenuga et al. 1992). Composting as a vehicle for biodegradation of oils containing waste solvents has been reported in Europe (Szabo et al. 1988).

\section{Disposal Without Treatment}

Disposal alternatives for contaminated CVWF solid residuals will be dictated by the type and level of contamination present in the sediments. Typically two alternatives exist:

a. Landfilling of nonhazardous sediments.

b. Disposal in a hazardous waste facility.

Contaminated sediments are managed by placement in a permanent CDF. This alternative applied to CVWF solid residuals would likely be viewed as operation of a hazardous waste landfill from a regulatory standpoint and would be subject to all applicable statutes.

Beneficial use is an additional disposal alternative for uncontaminated CVWF solids. In some cases, contaminated sediments may be suitable for beneficial uses if permitted by regulations and no significant adverse environmental effect could be expected. 


\section{Recommendations}

\section{Solid Residuals Management}

The principal concerns with respect to solid residuals management are as follows: (a) improvements in basin dewatering procedures or alternatives, and (b) a systematic approach to testing, treatment, and disposal requirements and technologies for CVWF residuals.

A summary of best available alternatives and recommendations follows.

\section{Dewatering}

There are a number of suitable technologies that can be applied to dewatering CVWF residuals. In-basin technologies are desirable because they eliminate one handling step and are inherently passive in nature. Operating limitations, however, particularly the amount of time required for effective residuals dewatering, will determine the feasibility of in-basin dewatering. Dewatering outside the basin may provide the highest overall system efficiency. The best dewatering alternatives appear to be one or a combination of the following:

a. Improving surface drainage so that the water level can be quickly brought down to the level of deposited sediment without carryover of fluid mud (see Design Modifications).

b. Cleaning sedimentation basins more frequently so that sediment deposits are more shallow, resulting in a shorter drainage path. Rate of consolidation occurs as the inverse of the square of the distance of the drainage path. Cutting sediment depth by one-half will theoretically decrease consolidation time to one-fourth of present levels. The same effect can be achieved with provision of additional vertical drainage paths, such as permeable baffles (sand berms) within the basin. Vertical drainage panels of polypropylene can be tried for in-basin drainage to see if dewatering time will be sufficiently reduced to utilize the method in basin. 
c. Using a sand or gravel underdrainage layer within the basin.

d. Removing sludge from the basin with sludge pumps and processing with the best available dewatering technology for sediment characteristics and site conditions; in this case, sand beds appear to be economical and adequate from a technical perspective.

\section{Testing}

A systematic testing approach that is in compliance with State and Federal regulations should be implemented to guide installation environmental coordinators toward appropriate treatment and disposal options.

\section{Physical/chemical treatment}

Biological. Continued land farming is appropriate where regulation and operational stability allow. Composting should be examined as a method for CVWF dewatering and treatment, especially at installations with sanitary treatment works. Although the regulatory environment is dynamic, stabilized biosolids from the sanitary treatment works might potentially be utilized as an amendment in the compost dewatering system. Currently, WES and CERL are working jointly to develop a mobile biocell system for the treatment of hydrocarbon-laden soils. This system may be applicable for CVWF residuals.

Solidification/stabilization. Solidification/stabilization has traditionally been the least-cost treatment alternative that has demonstrated application to heavy metals. For CVWF solids containing heavy metals above regulatory levels, the cost of solidification/stabilization and landfilling of stabilized waste should be compared with the overall cost and effectiveness of the other treatment technologies available and subsequent disposal requirements of those technologies. The least-cost alternative meeting regulatory requirements is expected to be the most desirable. The applicability of this process will be limited by the presence of organic contaminants, oil and grease (see Table 5).

\section{Other comments/recommendations}

Laboratory, pilot, or field testing may be necessary to determine which of these alternatives are most feasible and to select appropriate technologies. The presence of contaminants in the residuals will influence the suitability of certain of the alternatives, such as land spreading. Residuals containing unacceptable levels of contamination will have associated leachate and effluent waste streams that must also be addressed. State and Federal regulations will determine these requirements. Availability of space is also a determining factor in technology selection, particularly for land spreading and sand bed drying. It is recommended that operational changes be investigated for 
technical and economic effectiveness before technologies requiring changes to the physical plant are evaluated.

\section{Operational Procedures}

It is recommended that operational procedures be standardized to establish routine evaluation of sediments consistent with regulatory requirements and to provide for regular maintenance and cleaning of sedimentation basins. All systems should be maintained in working order. Provision for disposal of waste oil at the wash racks is needed to prevent illicit disposal in the wash water and subsequent contamination of sedimentation basin sediments.

The following operational modifications should be considered and evaluated in this order:

a. More frequent cleaning of primary sedimentation basins.

b. Improvements to in-basin drainage by addition of sacrificial underdrainage layer.

c. Intermittent removal of wet residuals into a residue management basin or sand-drying beds.

\section{Design Modifications}

The flow characteristics of the primary sedimentation basins at Fort Hood can be optimized to overcome the short circuiting presently seen as a result of mounding of coarse sediments in front of the inlet. Distribution of the influent in parallel troughs while maintaining sufficient flow velocity to prevent occlusion of the troughs will provide better distribution of the flow and sediment deposits. Where adequate secondary settling is provided, however, this is not considered to be a critical issue. At the Fort Hood installation, improvement to surface drainage to facilitate dewatering is a more important consideration. Three alternatives should be considered:

a. Replacing sluice gate with an adjustable weir.

b. Installing adjustable standpipes.

c. Modifying trough containing perforated pipe and gravel drainage bed to minimize occlusion and to provide surface drainage rather than bottom drainage.

The short circuiting seen in the secondary settling basins at Fort Hood should be addressed by relocation of the outlet further from the inlet or by installation of baffling to impose a longer fluid flow path. 


\section{Testing and Evaluation}

Field-, bench- or pilot-scale testing of selected technologies is recommended on a site-by-site basis. Priority for testing and evaluation should be established as follows:

a. In-basin dewatering alternatives.

(1) Operational modifications.

(2) In-basin dewatering technologies.

(3) System design modifications.

b. Out-of-basin dewatering alternatives.

(1) Sludge transfer mechanisms (pumps).

(2) Out-of-basin dewatering technologies.

c. Contaminant treatment/stabilization - site-specific testing of treatment systems/stabilization methods for contaminants of concern. 


\section{References}

Adenuga, A. O., Johnson, J. H., Cannon, J. N., and Wan, L. (1992). "Bioremediation of PAH-contaminated soil via in vessel composting," Water Science Technology 26(9-11), 2331-2334.

Alt, C. (1986). "Centrifugal separation." Advances in solid-liquid separation. H. S. Muralidhara, ed., Battelle Press, Columbus, OH, 107-139.

Atlas, R. M. (1975). "Effects of temperature and crude oil composition on petroleum biodegradation," Applied Microbiology 30, 396-403. . (1977). "Stimulated petroleum biodegradation," Critical Review of Microbiology 5, 371-386.

Averett, D. E., Perry, B. D., Torrey, E. J., and Miller, J. A. (1990). "Review of removal, containment and treatment technologies-forremediation of contaminated sediment in the Great Lakes," Miscellaneous Paper EL-90-25, U.S. Army Engineer Waterways Experiment Station, Vicksburg, MS.

Bartha, R., and Atlas, R. M. (1977). "The microbiology of oil spills," Advances in Applied Microbiology 22, 225-266.

Bartos, M. J., Jr. (1977). "Containment area management to promote natural dewatering of fine-grained dredged material," Technical Report D-7719, U.S. Army Engineer Waterways Experiment Station, Vicksburg, MS.

Bishop, A. W., and Vaughan, P. R. (1972). "Consolidation of fine grained dredged material after hydraulic deposition," Volume 1: Text, Department of Civil Engineering, Imperial College of Science and Technology, London, England.

Blumer, M., and Sass, J. (1972). "Oil pollution: Persistence and degradation of spilled fuel oil," Science 176, 1120-1122. 
Chang, F., Hult, M., and Noben, N. N. (1987). "Chapter 20, quantitative studies of biodegradation of petroleum and some model hydrocarbons in ground water and sediment environments." In: Biodegradation of Petroleum and Hydrocarbons, National Conference on Grand Water Quality and Agricultural Practices, Fairchild, D. M. (ed.), Lewis Publishers, 295-318.

Cheng, Y. S., and Chiang, S. H. (1990). "Filtration and dewatering of fine coal and refuse," Solid/liquid separation: Waste management and productivity enhancement. 1989 International Symposium, Battelle Press, Columbus, $\mathrm{OH}, 202-212$.

Colwell, R. R., and Walker, J. D. (1977). "Ecological aspects of microbial degradation of petroleum in the marine environment," Critical Review of Microbiology.

Dahlstrom, D. A. (1986). "Selection of solid-liquid separation equipment." Advances in solid-liquid separation. H. S. Muralidhara, ed., Battelle Press, Columbus, OH, 205-239.

Department of the Army. (1992). Technical Manual TM 5-814-9, Central vehicle wash facilities, 8 February 1992.

Ensminger, D. E. (1986). "Acoustic dewatering." Advances in solid-liquid separation. H. S. Muralidhara, ed., Battelle Press, Columbus, OH, 321334.

Hahn, W. J., and Loehr, R. C. (1992). "Biological treatment of oily petroleum šludges." 1992 Permian Basin Oil and Gas Recovery Conference Proceedings. 18-20 March 1992, 519-530.

Hogan, J. A., Toffoli, G. R., Miller, F. C., Hunter, J. V., and Finstein, M. S. (1989). "Composting physical model demonstration: Mass balance of hydrocarbons and PCBs," Aerobic and Anaerobic Biodegradation 742-758.

Johnson, S. J., Cunny, R. W., Perry, E. B., and Devay, L. (1977). “Stateof-the-art applicability of conventional densification techniques to increase disposal area storage capacity," Technical Report D-77-4, U.S. Army Engineer Waterways Experiment Station, Vicksburg, MS.

Kiang, Y., and Metry, A. A. (1982). Hazardous waste processing technology. Ann Arbor Science Publishers, Inc., The Butterworth Group, Ann Arbor, MI.

Lavanchy, A. C., Keith, F. W., and Beams, J. W. (1964). "Centrifugal separation." Encyclopedia of chemical technology. R. E. Kirk and D. F. Othmer, ed., 2d ed., Volume 4, Wiley Interscience, London, England, 710-758. 
Lockhart, N. C. (1986). "Electro-dewatering of fine suspensions." Advances in solid-liquid separation. H. S. Muralidhara, ed., Battelle Press, Columbus, OH, 241-274.

Loff, L. G. (1990). "Filter media, filter rating." Solid-liquid separation. L. Svarovsky, ed., Butterworths, London, England, 559-576.

Moudgil, B. M., and Shah, B. D. (1986). "Selection of flocculants for solidliquid separation processes." Advances in solid-liquid separation. H. S. Muralidhara, ed., Battelle Press, Columbus, OH, 191-204.

Mudroch, A., and MacKnight, S. D. (1991). CRC handbook of techniques for aquatic sediments sampling. CRC Press, Boca Raton, FL.

Muralidhara, H. S., Senapati, N., and Beard, R. B. (1986). "A novel electroacoustic separation process for fine particle suspensions." Advances in solid-liquid separation. H. S. Muralidhara, ed., Battelle Press, Columbus, $\mathrm{OH}, 335-374$.

Park, K. S., Sims, R. C., and Dupont, R. R. (1990). Transformation of PAHs in soil systems. Journal of Environmental Engineering, Volume 16, No. 3. May/June, 632-640.

Pierson, H. G. W. (1990). "The selection of solid-liquid separation equipment," Solid-liquid separation. L. Svarovsky, ed., Butterworths, London, England, 614-627.

Shafick, H. (1981). "Solid-liquid separation of fine particles." Proceedings of progress in dewatering of fine particles conference, April 1981, University of Alabama. 1-32.

Smith, G. R. S. (1990). "Filter aids." Solid-liquid separation. L. Svarovsky, ed., Butterworths, London, England, 338-357.

Snell Environment Group. (1982). "Final report on rate of biodegradation of toxic organic compounds while in contact with organics which are actively composting." National Science Foundation Project ISP 8113992, referenced as NSF/CEE-820 24, Washington, DC.

Svarovsky, L. (1990a). "Characterization of particles suspended in liquids." Solid-liquid separation. L. Svarovsky, ed., Butterworths, London, England, 11-42.

. (1990b). "Separation by centrifugal sedimentation." Solidliquid separation. L. Svarovsky, ed., Butterworths, London, England, 251-278. 
Szabo, Z., Horvath, A., Schiefner, K., Vargha, B., Dura, G., and Szabo, K. (1988). "Treatment of hazardous waste by composting." Hazardous waste: Detection, control, treatment. R. Abbou, ed., Elsevier Science Publishers B.V., Amsterdam.

Tiederman, W. G., and Reischman, M. M. (1973). "Feasibility study of hydrocyclone systems for dredge operations," Technical Report D-73-1, U.S. Army Engineer Waterways Experiment Station, Vicksburg, MS.

U.S. Army Corps of Engineers/U.S. Environmental Protection Agency. (1992). "Evaluating environmental effects of dredged material management alternatives - a technical framework," EPA842-B-92-008, Washington, DC.

U.S. Environmental Protection Agency. (1993). "Selecting remediation techniques for contaminated sediment," EPA-823-B93-001, Office of Water, Office of Science and Technology, Standards and Applied Science Division, Washington, DC, and Office of Research and Development, Risk Reduction Engineering Laboratory, Cincinnati, $\mathrm{OH}$.

- (1986). "Test methods for evaluating solid waste:

Physical/chemical methods (SW-846)," 3d ed. including Final Update 1 (July 1992), Government Printing Office, Washington, DC.

Wang, X., and Bartha, R. (1990). Effects of Bioremediation on Residues, Activity and Toxicity in Soil Contaminated by Fuel Spills. Soil Biology and Biochemistry, Volume 22, No. 4, 501-505.

Yusuf, M. (1991). "Detoxification of a contaminated sludge via in-vessel composting," ME thesis, Howard University, Washington DC.

Zeitsch, K. (1990). “Centrifugal filtration.” Solid-liquid separation. L. Svarovsky, ed., Butterworths, London, England, 476-540. 


\section{Bibliography}

Bishop, A. W., and Vaughan, P. R. (1972). "Consolidation of fine grained dredged material after hydraulic deposition, Volume 2: Tables \& figures," Department of Civil Engineering, Imperial College of Science and Technology, London, England.

Bricka, R. M., Holmes, T. T., Cullinane, M. J. (1992). "A comparative evaluation of two extraction procedures: The TCLP and the EP," Technical Report EL-92-33, U.S. Army Engineer Waterways Experiment Station, Vicksburg, MS.

Brown, N. P., and Heywood, N. I. (1991). Slurry handling design of solidliquid systems. Elsevier Applied Science, London, England.

Clarke, J. U., McFarland, V. A., and Pierce, B. D. (1989). "Preliminary recommendations for a congener-specific $\mathrm{PCB}$ analysis in regulatory evaluation of dredged materiaI," Miscellaneous Paper D-89-2, U.S. Army Engineer Waterways Experiment Station, Vicksburg, MS.

Cullinane, M. J., Averett, D. E., Shafer, R. A., Male, J. W., Truitt, C. L., and Bradbury, M. R. (1990). Contaminated dredged material, control, treatment and disposal practices. Noyes Data Corporation, Park Ridge, NJ.

- (1986). "Guidelines for selecting control and treatment options for contaminated dredged material requiring restrictions," U.S. Army Engineer Waterways Experiment Station, Vicksburg, MS.

Douglas, P. A. (1968). "Filter design criteria and their application," Auburn University, Auburn, AL.

Driscoll, E. D. (1986). "Detention and retention controls for urban runoff." Urban runoff quality - Impace and quality enhancement technology. Proceedings of an Engineering Foundation Conference, June 23-27, 1986, Henniker, New Hampshire, American Society of Engineers, New York. 
Durand, P. R., and de Lara, G. C. (1954). "Settling velocity of sand grains in fluids in an infinite medium," U.S. Department of the Interior, Bureau of Reclamation, Denver, CO.

Environmental Engineering Consultants, Inc. (1976). “Laboratory study of aeration as a feasible technique for dewatering fine-grained dredged material," Contract Report D-76-10, U.S. Army Engineer Waterways Experiment Station, Vicksburg, MS.

Haliburton, T. A. (1978). "Guidelines for dewatering/densifying confined dredged material," Technical Report DS-78-11, U.S. Army Engineer Waterways Experiment Station, Vicksburg, MS.

Haliburton, T. A., Durham, G. N., Brown, K. W., Peters, R. E., and Delaney, T. B., Jr. (1977). "Effects of mechanical agitation on drying rate of fine-grained dredged material," Technical Report D-77-10, U.S. Army Engineer Waterways Experiment Station, Vicksburg, MS.

Haliburton, T. A., and Hayes, C. (1980). "Evaluation of dredged material dewatering alternatives for the Craney Island Disposal Area, Norfolk, Virginia," Haliburton Associates for the U.S. Army Engineer Waterways Experiment Station, Vicksburg, MS.

Hammer, D. P. (1981). "Evaluation of underdrainage techniques for the densification of fine-grained dredged material," Technical Report EL-81-3, U.S. Army Engineer Waterways Experiment Station, Vicksburg, MS.

Herbich, J. B. (1992). Handbook of dredging engineering. McGraw-Hill, Inc., New York.

Hoover, T. P. (1981). "Nonwoven geotextile fabrics: Evaluation and specification for subdrainage filtration," FHWA/CA/TL-81/11, Office of Transportation Laboratory, California Department of Transportation, Sacramento, CA.

Jones, R. H., Williams, R. R., and Moore, T. K. (1978). "Development and application of design and operation procedures for coagulation of dredged material slurry and containment area effluent," Technical Report D-78-54, U.S. Army Engineer Waterways Experiment Station, Vicksburg, MS.

Klesch, W. L. (1987). "Long-term management strategy (LTMS) for the disposal of dredged material: Corps-wide implementation," Environmental Effects of Dredging Information Exchange Bulletin, Volume D-87-4, U.S. Army Engineer Waterways Experiment Station, Vicksburg, MS.

Kostecki, P. T., and Calabrese, E. J. (1990). Petroleum contaminated soils, Volume 3. Lewis Publishers, Chelsea, MI. 
Lee, C. R., Hoeppel, R. E., Hunt, P. G., and Carlson, C. A. (1976). "Feasibility of the functional use of vegetation to filter, dewater, and remove contaminants from dredged material," Technical Report D-76-4, U.S. Army Engineer Waterways Experiment Station, Vicksburg, MS.

Lee, C. R., Peddicord, R. K., Folsom, B. L., Jr., Francingues, N. R., Jr., Montgomery, R. L., and Palermo, M. R. (1986). "Application of the resource conservation and recovery act of 1976 to dredged material," Internal Working Document D-86-1, U.S. Army Engineer Waterways Experiment Station, Vicksburg, MS.

Long, B. W., Grana, D. J. (1978). "Feasibility study of vacuum filtration systems for dewatering dredged material," Technical Report D-78-5, U.S. Army Engineer Waterways Experiment Station, Vicksburg, MS.

Male, J. W., and Cullinane, M. J., Jr. (1988). "A procedure for managing contaminated dredged material," University of Massachusetts, Amherst, MA, and U.S. Army Engineer Waterways Experiment Station, Vicksburg, MS.

Montgomery, R. L. (1978). "Methodology for design of fine-grained dredged material containment areas for solids retention," Technical Report D-78-56, U.S. Army Engineer Waterways Experiment Station, Vicksburg, MS.

Montgomery, R. L., Thackston, E. L., and Parker, F. L. (1983). "Dredged material sedimentation basin design," Journal of Environmental Engineering 109(2), 466-484.

Moudgil, B. M., and Somasundara, P. (1985). "Flocculation, sedimentation and consolidation." Proceedings of the Engineering Foundation Conference, January 27-February 1, 1985, Sea Island, Georgia. Engineering Foundation, American Institute of Chemical Engineers, Florida Institute of Phosphate Research and National Science Foundation.

Muralidhara, H. S., ed. (1990). Solid/liquid separation: Waste management and productivity enhancement, 1989 international symposium. Battelle Press, Columbus, $\mathrm{OH}$.

\section{Columbus, $\mathrm{OH}$.}

(1986). Advances in solid-liquid separation. Battelle Press,

Nawrocki, M. A. (1974). "Demonstration of the separation and disposal of concentrated sediments," EPA-660/2-74-072, Office of Research and Development, U.S. Environmental Protection Agency, Washington, DC. 
Palermo, M. R. (1977). "An evaluation of progressive trenching as a technique for dewatering fine-grained dredged material," Miscellaneous Paper D-77-4, U.S. Army Engineer Waterways Experiment Station, Vicksburg, MS.

Patin, T. R., ed. (1987). "Management of bottom sediments containing toxic substances." Proceedings of the 13th U.S./Japan Experts Meeting, 35 November, Baltimore, Maryland. Water Resources Support Center, Fort Belvoir, Virginia, and U.S. Army Engineer Waterways Experiment Station, Vicksburg, MS.

Peters, R. W., and Bennett, G. F. (1990). "Dissolved air, induced air, and nozzle air flotation system performance comparison for precipitation/ flotation of metal-laden wastewaters." Solid/liquid separation: Waste management and productivity enhancement, 1989 international symposium, Battelle Press, Columbus, OH, 162-187.

Phillips, D. E., Malek, J. F., and Hamner, W. B. (1985). "Evaluation of alternative dredging methods and equipment, disposal methods and sites, and site control and treatment practices for contaminated sediments," U.S. Army Engineer District, Seattle, WA.

Ramaswami, D. (1990). "Effect of sludge solids properties on sludge dewatering operations," University of Wisconsin-Milwaukee.

Salomons, W., and Förstner, U., ed. (1988). Environmental management of solid waste. Springer-Verlag, Berlin, Heidelberg Germany.

Shields, F. D., Jr., Thackston, E. L., Schroeder, P. R., Bach, D. P. (1987). "Design and management of dredged material containment areas to improve hydraulic performance," Technical Report D-87-2, U.S. Army Engineer Waterways Experiment Station, Vicksburg, MS.

Sims, R., Sorensen, D., Sims, J., McLean, J., Mahmood, R., Dupont, R., Jurinak, J., and Wagner, K. (1986). Contaminated surface soils in-place treatment techniques. Noyes Publications, Park Ridge, NJ.

Smith, M. A. (1985). Contaminated land, reclamation and treatment. Plenum Press, New York.

Sukok, R. B., and McNelly, G. D. (1990). "Workshop on innovative technologies for treatment of contaminated sediments, summary report, June 13-14, 1990," EPA/600/2-90/054, Risk Reduction Engineering Laboratory, Office of Research and Development, U.S. Environmental Protection Agency, Cincinnati, $\mathrm{OH}$. 
Teeter, A. M., and Pankow, W. (1989). "The Atchafalaya River delta, Report 2, field data, Section 2: Settling characteristics of bay sediments," Technical Report HL-82-15, U.S. Army Engineer Waterways Experiment Station, Vicksburg, MS.

Teindl, H. (1980). "Filter criteria of geotextiles," Federal Ministry for Construction and Technology, Road Building, Issue No. 153, Vienna, Austria.

U.S. Army Corps of Engineers. (1941). "Investigation of filter requirements for underdrains," Technical Memorandum No. 183-1, U.S. Army Engineer Waterways Experiment Station, Vicksburg, MS.

U.S. Environmental Protection Agency. (1985). "Remedial action at waste disposal sites (revised)," EPA/625/6-85/006, Hazardous Waste Engineering Research Laboratory, Cincinnati, $\mathrm{OH}$.

U.S. Environmental Protection Agency/U.S. Army Corps of Engineers. (1991). "Evaluation of dredged material proposed for ocean disposal (testing manual)," EPA-503/8-91/001, Washington, DC.

Wagner, K., Boyer, K., Claff, R., Evans, M., Henry, S., Hodge, V., Mahmud, S., Sarno, D., Scopino, E., and Spooner, P. (1986). Remedial action technology for waste disposal sites. Noyes Data Corporation, Park Ridge, NJ.

Wang, C., and Chen, K. Y. (1977). "Laboratory study of chemical coagulation as a means of treatment for dredged material," Technical Report D77-39, U.S. Amy Engineer Waterways Experiment Station, Vickisburg, MS.

Wardlaw, C. "Remediation of contaminated sediment: General decision making principles and overview of the ex-situ treatment options," Wastewater Technology Centre, Burlington, Ontario, Canada. 


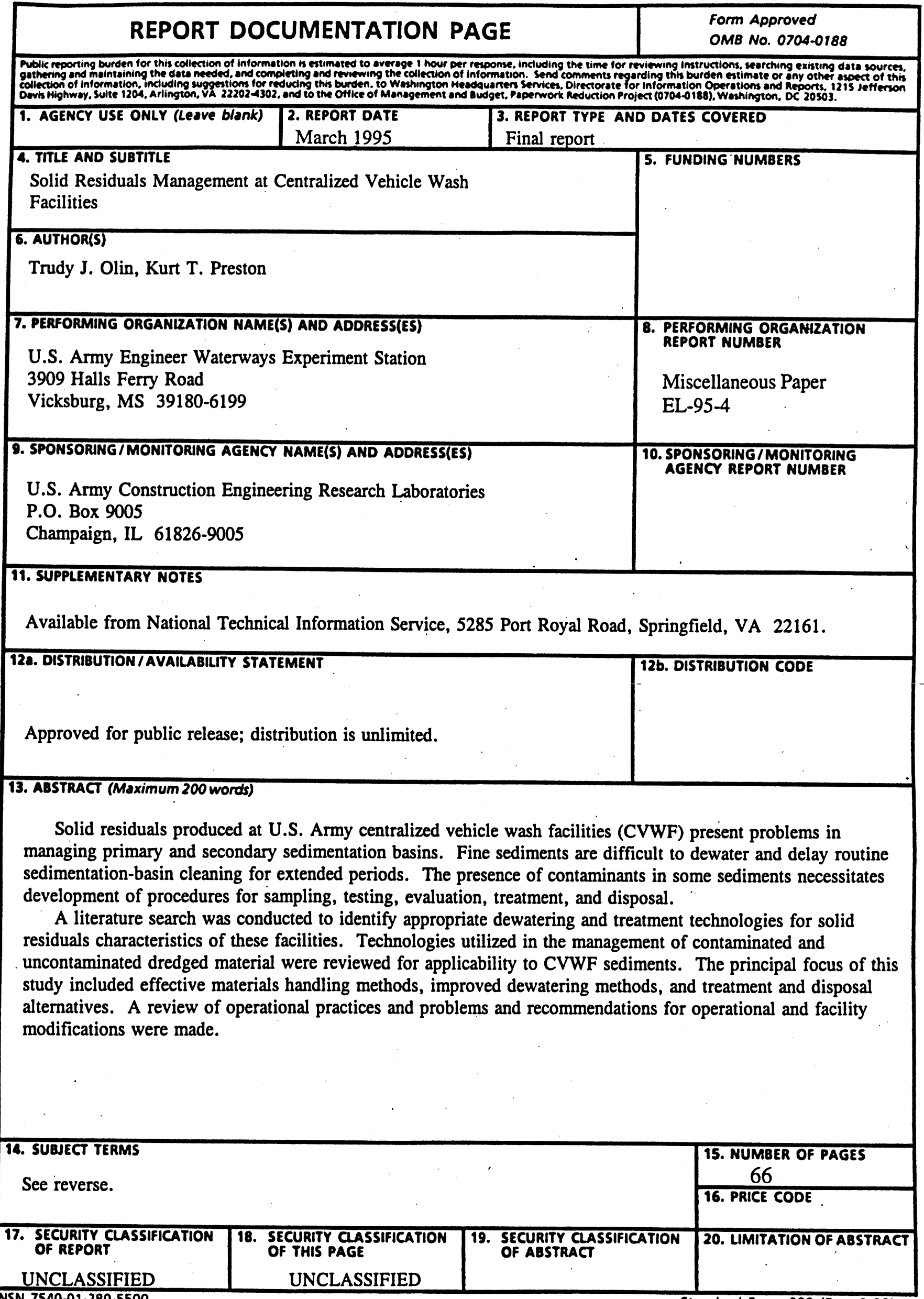


14. (Concluded).

\section{Contaminants}

CVWF (Centralized vehicle wash facility)

Dewatering

Disposal

Operational problems and recommendations

Particle classification

Sampling

Testing

Treatment 